OPEN ACCESS

Edited by: Daniele Vergara,

University of Salento, Italy

Reviewed by:

Sara Sergio,

University of Salento, Italy

Anna Maria Giudetti,

University of Salento, Italy

${ }^{*}$ Correspondence:

Stefano Fiorucci

Stefano.fiorucci@unipg.it

${ }^{+}$These authors have contributed equally to this work

Specialty section: This article was submitted to

Cancer Genetics,

a section of the journal

Frontiers in Oncology

Received: 03 February 2021 Accepted: 06 April 2021

Published: 03 May 2021

Citation:

Carino A, Graziosi L, Marchianò S,

Biagioli M, Marino E, Sepe V,

Zampella A, Distrutti E, Donini $A$ and

Fiorucci S (2021) Analysis of Gastric

Cancer Transcriptome Allows the

Identification of Histotype Specific

Molecular Signatures With

Prognostic Potential.

Front. Oncol. 11:663771.

doi: 10.3389/fonc.2021.663771

\section{Analysis of Gastric Cancer Transcriptome Allows the Identification of Histotype Specific Molecular Signatures With Prognostic Potential}

\author{
Adriana Carino ${ }^{1 \dagger}$, Luigina Graziosi $^{2 \dagger}$, Silvia Marchianò ${ }^{1}$, Michele Biagioli ${ }^{1}$, Elisabetta \\ Marino $^{2}$, Valentina Sepe ${ }^{3}$, Angela Zampella ${ }^{3}$, Eleonora Distrutti ${ }^{2}$, Annibale Donini ${ }^{1}$ \\ and Stefano Fiorucci ${ }^{{ }^{*}}$ \\ ${ }^{1}$ Department of Medicine and Surgery, University of Perugia, Perugia, Italy, ${ }^{2}$ S.C.Gastroenterologia, Azienda Ospedaliera di \\ Perugia, Perugia, Italy, ${ }^{3}$ Department of Pharmacy, University of Naples Federico II, Naples, Italy
}

Gastric cancer is the fifth most common malignancy but the third leading cause of cancerassociated mortality worldwide. Therapy for gastric cancer remain largely suboptimal making the identification of novel therapeutic targets an urgent medical need. In the present study we have carried out a high-throughput sequencing of transcriptome expression in patients with gastric cancers. Twenty-four patients, among a series of 53, who underwent an attempt of curative surgery for gastric cancers in a single center, were enrolled. Patients were sub-grouped according to their histopathology into diffuse and intestinal types, and the transcriptome of the two subgroups assessed by RNAseq analysis and compared to the normal gastric mucosa. The results of this investigation demonstrated that the two histopathology phenotypes express two different patterns of gene expression. A total of 2,064 transcripts were differentially expressed between neoplastic and non-neoplastic tissues: 772 were specific for the intestinal type and 407 for the diffuse type. Only 885 transcripts were simultaneously differentially expressed by both tumors. The per pathway analysis demonstrated an enrichment of extracellular matrix and immune dysfunction in the intestinal type including CXCR2, CXCR1, FPR2, CARD14, EFNA2, AQ9, TRIP13, KLK11 and GHRL. At the univariate analysis reduced levels AQP9 was found to be a negative predictor of 4 years survival. In the diffuse type low levels CXCR2 and high levels of CARD14 mRNA were negative predictors of 4 years survival. In summary, we have identified a group of genes differentially regulated in the intestinal and diffuse histotypes of gastric cancers with AQP9, CARD14 and CXCR2 impacting on patients' prognosis, although CXCR2 is the only factor independently impacting overall survival.

Keywords: gastric cancer, adenocarcinoma, biomarkers, tumor microenvironment, transcriptome (RNA-seq) 


\section{INTRODUCTION}

Gastric cancer is a highly prevalent cancer representing the fifth most frequent cancer worldwide (1-3). While gastric cancer incidence has shown a trend of reduction over the last decades, gastric cancer-related mortality remains the third cause of cancer-related deaths worldwide. In Western countries, due to a lack of validated cancer screening programs, the large majority patients with gastric cancer are diagnosed in the advanced stages, greatly limiting the therapeutic options. Surgery remains the only potentially curative treatment, although current evidence supports adoption of perioperative therapies to improve a patient's survival (2). Peritoneal metastases are the most frequent metastases detected in patients with advanced gastric cancers and the peritoneal cavity is a common site for gastric cancer recurrence following surgery $(4,5)$. Overall, the presence of peritoneal carcinosis is associated to reduced survival rates and overwhelming symptoms $(6,7)$.

Two histopathology subtypes of gastric adenocarcinomas, intestinal (well-differentiated) and diffuse (undifferentiated), with a distinct morphologic appearance, pathogenesis, and genetic profiles have been identified (8-10). The diffuse gastric cancer type is clinically more aggressive and associates with a higher rate of peritoneal involvement compared to the intestinal type $(11,12)$. However, the current histopathologic system fails to reflect the molecular and genetic heterogeneity of gastric cancers, and it is of clinical relevance to molecularly investigate gastric cancers in the attempt to identify novel targets for the prevention and treatment (9).

Several studies have shown a robust molecular heterogeneity of gastric adeno-carcinomas leading to different molecular classifications $(11,13,14)$. A widely used molecular classification proposed by the Genome Atlas Research Network Group (TCGA) has identified four major tumor molecular subtypes: Epstein-Barr virus positive, microsatellite unstable tumors, genomically stable tumors and tumors with chromosomal instability (14). Although these subtypes have shown poor correlation with the prognosis, they have proven partially helpful in the selection of chemotherapy approaches suggesting that molecular profiling rather than histology could be implemented as a guide for the choice of treatment modality. Currently, only few biomarkers are available to predict treatment effectiveness in gastric cancer's patients including the level of expression of human epidermal growth factor receptor 2 (HER2) for trastuzumab and the programmed death-ligand 1 (PD-L1) for pembrolizumab $(15,16)$, the last one allowed as a second line therapy for metastatic disease.

The introduction of Next Generation Sequencing (NGS), such as the RNA-sequencing technology, allows the application of large-scale functional genomics to cancer research and its application in clinical settings might allow the identification of individual gene expression profiles to be used as a potential biomarkers in the treatment of gastric cancer $(17,18)$. Previous studies have investigated differentially expressed genes between gastric cancer tissues and healthy gastric mucosa $(17,19,20)$.
Moreover, several studies have identified stage-specific gene expression profiles and histological specific-gene profiles (21, $22)$. In this study, we report an integrative analyses of transcriptome sequencing (RNA-seq) and clinical and pathological characterization of patients with gastric cancers. We performed the NGS analysis based on histological types. Our principal goal was to identify new transcripts to be used as gastric cancer biomarkers and to which attribute a prognostic survival value. This novel comparative analysis generated a large amount of information that could be exploited to identify underlying molecular mechanisms of carcinogenesis, detection of disease markers and the identification of novel therapeutic targets.

\section{MATERIALS AND METHODS}

\section{Patients and Specimens}

Surgical specimen of 53 patients curatively operated for gastric cancers, were collected and analyzed according to the Helsinki declaration. Permission to collect post-surgical samples was granted to Prof. Fiorucci by the ethical committee of Umbria (CEAS). Permit FI00001, n. 2266/2014 granted on February 19, 2014. An informed written consent was obtained by each patient before surgery.

Clinical data of these patients were retrieved from a prospectively collected database of GC patients operated between October 2014 and August 2017 at the Department of Surgery, Santa Maria della Misericordia Hospital (Italy). None of the patients received chemotherapy or radiation before surgery. All patients were followed up regularly until death every 6 months for the first 2 years from surgery and every year thereafter.

The study population includes 24 patients that were selected according to preoperative factors such as sex, age, gender, preoperative serum albumin level, preoperative N/l ratio (neutrophils to lymphocytes ratio); surgery related factors such as surgery type, lymphadenectomy level dissection, number of lymph nodes retrieved; associated organ resections and tumor related factors such as Lauren's Histotype, tumor location, pathological stage according to AJCC tnm 8th edition (23) and peritoneal carcinomatosis development.

Venous blood sample was taken either the day before surgery or few days immediately before and collected in ethylenediaminetetraacetic acid-containing tube. The normal range of white blood cell (WBC) count was from 4,000 to 10,800 cells $/ \mathrm{mm}^{3}$ and $3.5-4$. The normal range of albumin was from 3.5 to $5.2 \mathrm{~g} / \mathrm{dl}$. N/L was calculated as neutrophil count divided by lymphocyte count. The patients were dichotomized at the median value of NLR, whereas patients were dichotomized according to the lower physiologic albumin levels for both intestinal and diffuse groups (Table 1).

Finally, patients were separated in to two subgroups according to the median value of gene expression to perform OS analysis. The healthy samples used as controls were obtained from the tumor-free surgical resection margins of the same patients. 
TABLE 1 | Clinical and pathological characteristics of the study population $(n=24)$.

\begin{tabular}{|c|c|c|c|}
\hline Patients & Intestinal $(n=12)$ & Diffuse $(n=12)$ & $\mathbf{P}$ \\
\hline \multicolumn{4}{|l|}{ Gender: } \\
\hline \multicolumn{4}{|l|}{ pT: } \\
\hline - 1 & 0 & 0 & \multirow[t]{2}{*}{ N.S. } \\
\hline - 2 & 0 & $1(8.3 \%)$ & \\
\hline \multicolumn{4}{|l|}{$\mathrm{pN}:$} \\
\hline - NO & $1(8.3 \%)$ & $1(8.3 \%)$ & \multirow[t]{4}{*}{ N.S. } \\
\hline - N1 & 1 (8.3\%) & 0 & \\
\hline - $\quad \mathrm{N} 2$ & $3(25 \%)$ & $4(33.3 \%)$ & \\
\hline - N3 & $7(58.4)$ & $7(58.4)$ & \\
\hline \multicolumn{4}{|l|}{ Stage: } \\
\hline Lymphonodal Harvested $^{\star *}$ : & 38.5 & 37 & N.S. \\
\hline Lymphonodal Ratio** & 0.2 & 0.3 & N.S. \\
\hline \multicolumn{4}{|l|}{ Tumor Location: } \\
\hline * $U$ & $2(16.7 \%)$ & $4(33.3 \%)$ & \multirow[t]{3}{*}{ N.S. } \\
\hline * $\mathrm{M}$ & $6(50 \%)$ & $5(41.7 \%)$ & \\
\hline * $L$ & $4(33.3 \%)$ & $3(25 \%)$ & \\
\hline \multicolumn{4}{|l|}{ Lymphoadenectomy: } \\
\hline * D1 & $1(8.3 \%)$ & $2(16.7 \%)$ & \multirow[t]{3}{*}{ N.S. } \\
\hline * D2 & $11(91.7 \%)$ & $9(75 \%)$ & \\
\hline * D3 & 0 & $1(8.3 \%)$ & \\
\hline Multiorgan resection: & $2(16.7 \%)$ & $3(25 \%)$ & N.S. \\
\hline Peritoneal Carcinomatosis development: & $4(33.3 \%)$ & $8(66.6 \%)$ & N.S. \\
\hline$N / L$ ratio**: & 2.3 & 3.5 & N.S. \\
\hline
\end{tabular}

${ }^{*}$ Mean \pm Dev. St.

**Median value.

${ }^{* * *}$ deviation from the physiological value.

N.S., not statistical.

\section{Statistical Analysis}

Patient's descriptive analysis was generated, and their differences were investigated using Student $\mathrm{t}$-test for quantitative data; for qualitative data, we used either Fisher's exact test or chi-square test. To compare overall survival (OS) between groups, the cumulative survival proportions were calculated using the product limit method of Kaplan-Meier, and differences were evaluated using the log-rank test. Only variables that achieved statistical significance in the univariate analysis were subsequently evaluated in the multivariate analysis using Cox's proportional hazard regression model. A p value of less than 0.05 was considered statistically significant. All statistical analyses were performed using the MedCalc Statistical Software version 14.8.1 (MedCalc Software bvba, Ostend, Belgium) and PRISM 7.2 Graph PAD.

\section{AmpliSeq Transcriptome}

High-quality RNA was extracted from tumor gastric mucosa and healthy mucosa using the PureLink ${ }^{\mathrm{TM}}$ RNA Mini Kit (Thermo Fisher Scientific), according to the manufacturer's instructions. RNA quality and quantity were assessed with the
Qubit $^{\circledR}$ RNA HS Assay Kit and a Qubit 3.0 fluorometer followed by agarose gel electrophoresis. Libraries were generated using the Ion AmpliSeq ${ }^{\mathrm{TM}}$ Transcriptome Human Gene Expression Core Panel and Chef-Ready Kit (Thermo Fisher Scientific), according the manufacturer's instructions. Briefly, $10 \mathrm{ng}$ of RNA was reverse transcribed with SuperScript ${ }^{\mathrm{TM}}$ Vilo $^{\mathrm{TM}}$ cDNA Synthesis Kit (Thermo Fisher Scientific, Waltham, MA) before library preparation on the Ion Chef ${ }^{\mathrm{TM}}$ instrument (Thermo Fisher Scientific, Waltham, MA). The resulting cDNA was amplified to prepare barcoded libraries using the Ion Code ${ }^{\mathrm{TM}}$ PCR Plate, and the Ion AmpliSeq $^{\mathrm{TM}}$ Transcriptome Mouse Gene Expression Core Panel (Thermo Fisher Scientific, Waltham, MA), Chef-Ready Kit, according to the manufacturer's instructions. Barcoded libraries were combined to a final concentration of $100 \mathrm{pM}$, and used to prepare Template-Positive Ion Sphere ${ }^{\mathrm{TM}}$ (Thermo Fisher Scientific, Waltham, MA) Particles to load on Ion $540^{\mathrm{TM}}$ Chips, using the Ion $540^{\mathrm{TM}}$ Kit-Chef (Thermo Fisher Scientific, Waltham, MA). Sequencing was performed on an Ion $5^{\mathrm{TM}}$ Sequencer with Torrent Suite ${ }^{\mathrm{TM}}$ Software v6 (Thermo Fisher Scientific). The analyses were performed with a range of 
fold $<-2$ and $>+2$ and a $\mathrm{p}$ value $<0.05$, using Transcriptome Analysis Console Software (version 4.0.2), certified for AmpliSeq analysis (Thermo-Fisher). The transcriptomic data have been deposited as dataset on Mendeley data repository (10.17632/d3ykf83tyv.1).

\section{Functional Enrichment Analysis}

DAVID software was employed to identify significantly enriched Gene Ontology functions in biological processes (BP), molecular function, and cellular component (CC) categories for histotypespecific genes (24).

\section{RESULTS}

\section{Patients}

This study includes 24 gastric cancer patients who underwent resection surgery in our department between October 2014 and August 2017. This cohort of patients was further subdivided into two groups according to Lauren classification, as such two group of gastric cancer patients were identified: "intestinal group" and "diffuse group" (Table 1). The two groups include 12 patients each and were highly homogeneous as indicated in Table 1, in terms of mean age, gender and cancer stage. All patients underwent either a total or subtotal gastrectomy plus D1, D2 or D3 lymphadenectomy with a median number of harvested lymph nodes of 38.5 for intestinal group and 37 for diffuse group. The distribution of cancer stages (TNM8) was as follows: stage II: one (8.3\%), stage III: eight (66.7\%), stage IV: three $(25 \%)$ for intestinal group; stage III: six (50\%), stage IV: six $(50 \%)$ for diffuse group (Table 1). For survival analysis two patients in each group were excluded due to early postoperative death.

\section{Transcriptome Analysis: Identification of Common Markers That Characterized Both Diffuse and Intestinal Gastric Cancer From Healthy Mucosa}

We performed an AmpliSeq Transcriptome analysis (RNA-seq) of 24 gastric tumors (and their matched normal tissues), according to the Lauren classification, as described in Materials and Methods section. As shown in Figure 1, the PCoA analysis revealed that healthy samples showed a homogeneous distribution, whereas both diffuse and intestinal tumors showed dissimilarities compared to normal tissues, but their signals only partially overlap (Figure 1A). The Scatter Plots depicted in Figure 1B, identify transcripts differentially expressed between diffuse tumor and healthy mucosa, or intestinal tumor and healthy mucosa.

The Venn Diagram analysis of differentially expressed transcripts, confirmed that the gene signature of diffuse and intestinal gastric cancer only partially overlaps. We have identified the subset AB (885 transcripts) containing genes differentially expressed both in diffuse and intestinal gastric cancer vs healthy mucosa (Figure 2). These transcripts resulted modulated in same direction in both gastric cancer histotypes, confirming the existence of common molecular mechanisms underlying the development of the two main histological types of gastric cancer.

We have also detected transcripts differentially modulated only in diffuse gastric cancer vs healthy mucosa (Subset A containing 407 genes), and transcripts differentially modulated only in intestinal cancer vs healthy mucosa (Subset B containing 772 genes). These findings suggest that each gastric cancer
A

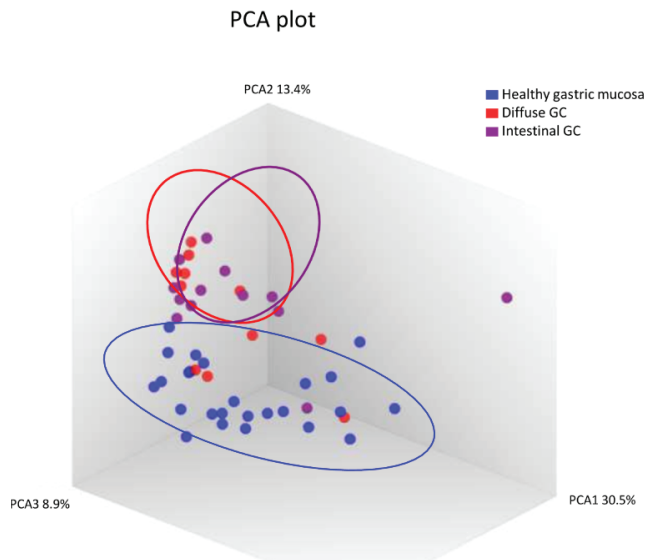

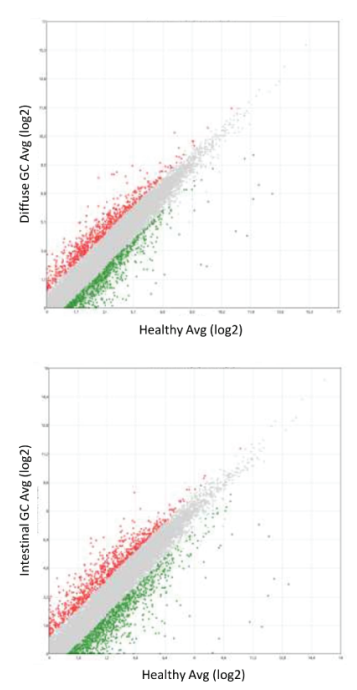

FIGURE 1 | RNA sequencing of Diffuse and Intestinal Gastric Cancer. (A) Heterogeneity characterization of gastric samples showed by principal component analysis (PCA) plot. (B) Scatter plots of transcripts differentially expressed between diffuse gastric cancer and healthy mucosa or intestinal gastric cancer and healthy mucosa. (Fold Change $<-2$ or $>+2$, p value $<0.05$ ). 


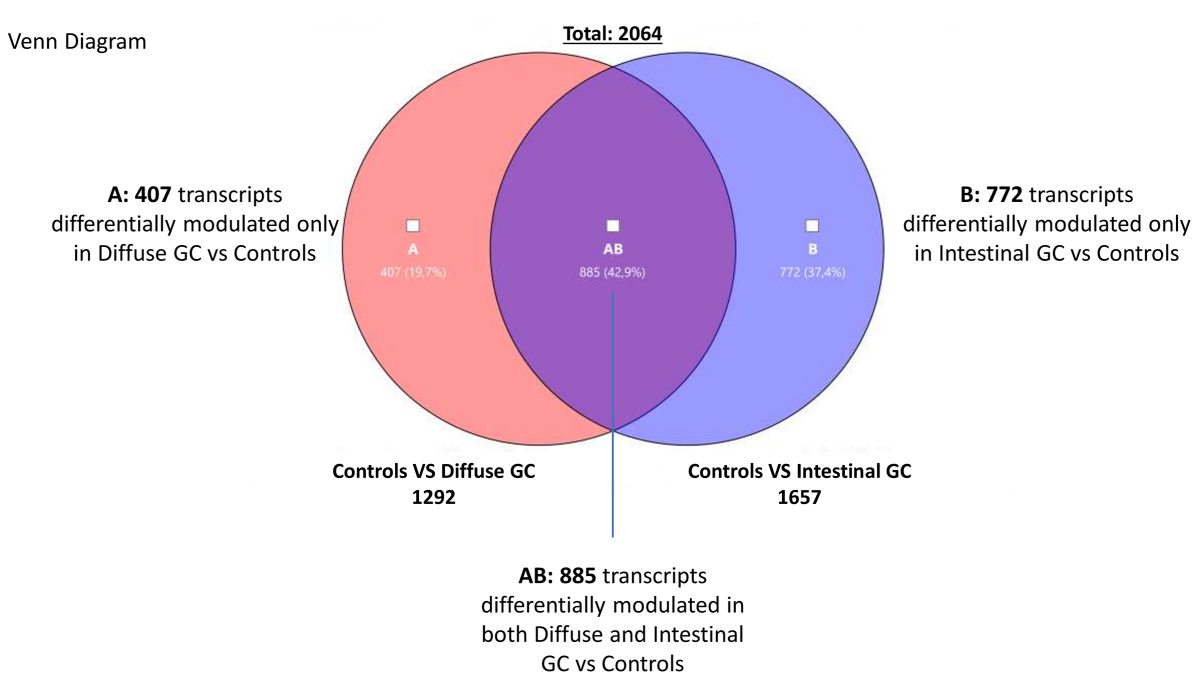

FIGURE 2 | Transcriptome analysis. Venn Diagram analysis of differentially expressed genes in Diffuse (subset A) and Intestinal (subset B) gastric cancer samples compared with healthy mucosa, showing the overlapping region (identified AB subset) containing transcripts differentially expressed in both gastric cancer histotypes (Fold Change $<-2$ or $>+2$, p value $<0.05$ ).

histotype is characterized by specific molecular patterns. Therefore, we have performed a per pathways analysis of these different gene subsets using TAC software, to better dissect the most modulated mechanisms in diffuse and intestinal gastric cancers. For each subset (AB, A and B) we found several pathways that can be grouped in three principal clusters: a) proliferation, differentiation and metabolism; b) inflammation and c) signaling. As expected, we found that the two types of gastric cancer (Subset $\mathrm{AB}$ ) showed similar features regarding the modulation of genes involved in cell cycle, mitosis, cell division, DNA replication, extracellular matrix, as well as in the regulation of inflammation (IL-18, Chemokines, Cytokines, IL6 signaling pathways), or in cancer development and progression (PI3KAkt-mTOR, VEGFA-VEGFR2, MAPK, Ras, EGF/EGFR signaling pathways), which differentiate both histotypes from healthy mucosa (see Supplementary Tables 1-3).

In particular, we found an upregulation of several cell cycle regulators (Supplementary Table 1) such as the cyclindependent kinase CDK1, that induces the growth of gastric cancer cells (25), the M-phase inducers CDC25A and $\mathrm{CD} 2 \mathrm{C} 5 \mathrm{~B}$, which increased expression represents an early event in gastric carcinogenesis common to both diffuse and intestinal cancer (26), the Cyclin B1 and B2 (CCNB1, CCNB2), upregulated to promote gastric cancer cell proliferation and tumor growth $(27,28)$, or the E2Fs family and the correlated MYBL2 proto-oncogene, associated with cancer progression and poor overall survival $(29,30)$. Importantly we found also a modulation of genes involved in Epithelial to Mesenchymal Transition including TMPRSS4, that is upregulated in gastric cancer and increased the invasiveness of gastric cancer cells activating NF-Kb/MMP9 signaling (31), and Claudins (CLDN1, CLDN3, CLDN4, CLDN7), overexpressed in gastric cancer and associated with gastric cancer cell proliferation, invasion and maintenance of mesenchymal state (32-34). Furthermore, we found an overexpression of ITGA2, which regulates Metastases and EMT (35), LAMC2 and WNT5A genes, that mediate invasion of gastric cancer cells (36). Finally, great of relevance, we found an upregulation of Matrix Metalloproteinase family (MMP1, MMP3, MMP10, MMP12), that are overexpressed in gastric cancer as a result of NF-Kb activation thus promoting migration and invasion, and are associated with poor prognosis (37-40). Among most downregulated genes we found GPX3, PTGER3 and LIPF $(-47.5$ and -435.63 of fold change for Diffuse and Intestinal tumors respectively), that resulted hypermethylated in gastric cancer $(41,42)$.

The analysis of immune cluster revealed a great modulation of chemokine and cytokine signaling pathways (Supplementary Table 2). In particular, we found an upregulation of CCL3, CCL15, both overexpressed in the stromal compartment of gastric cancer (43), CCL20, that activates the pErk1/2-pAkt signaling via CCR6 inducing EMT pathways (44), but also CXCLs family (CXC1, CXCL2, CXCL5 and CXCL16), that are induced by Cox $2 /$ Pge 2 or Wnt5a signaling $(45,46)$, and correlate with tumor malignant progression, invasiveness, gastric cancer cell migration and metastasis via the activation of CXCR2/Stat3 pathway (47-50).

We also detected an upregulation of several cytokines including IL-1 $\beta$, IL-11 and IL-8, that promote metastasis, anti-apoptotic effects and maintenance of stemless properties by activating PI3K, JAK/STAT3 and NF-kB signaling pathways respectively (51-53). Interestingly, we detected a downregulation of AQP4, which, when overexpressed, reduce gastric cancer cells proliferation (54).

The analysis of signaling cluster (Supplementary Table 3), revealed the upregulation of ANGPT2, whose overexpression promotes angiogenesis in gastric cancer (55), and S100A2, which 
is associated with tumor progression (56), whereas the expression of several genes was downregulated, including: CAB39L, a tumor suppressor hypermethylated in gastric cancer cells and tissues (57), HIF3A and SFRP1, targeted by several specific miRNA overexpressed in gastric cancer (58-60), and FABP4, whose expression in Tissue-resident memory $\mathrm{T}$ cells (Trms) infiltrating the tumor is reduced by PD-L1 activation (61).

Furthermore, among overexpressed genes in both gastric cancer types, we found CEACAM1 and CEACAM6, two recognized markers of angiogenesis, invasion and metastasis in gastric cancer $(62,63)$. Finally, we also detected a modulation of genes that have been identified as tumor suppressors in other cancer types, including OGN, a gene that is downregulated in the breast cancer and that functions as $\mathrm{PI} 3 \mathrm{~K} / \mathrm{AKT} / \mathrm{mTOR}$ suppressor (64).

\section{Transcriptome Analysis: Identification of Markers Specific for Diffuse Gastric Cancer}

To better characterize the specific phenotype of Diffuse Gastric cancer, we have then investigated the subset A of Venn Diagram (Figure 3). The analysis of this subset of genes, highlighted a modulation of transcripts involved in lipid metabolism and transport, metabolic pathways and transcription (Table 2).

In particular, we found an upregulation of several genes involved in proliferation and lipid metabolism such as HNF4A, functionally required for the development of gastric cancer regulating IDH1 (65), APOC1, recognized as new diagnostic and prognostic marker of gastric cancer (66), APOE, which is highly expressed in gastric cancers and correlates with progression and invasion $(67,68)$, FASN associated with diffuse gastric cancer and poor prognosis (69).

Analysis of Subset A: 407 transcripts differentially modulated only in Diffuse GC vs Healthy Gastric Mucosa
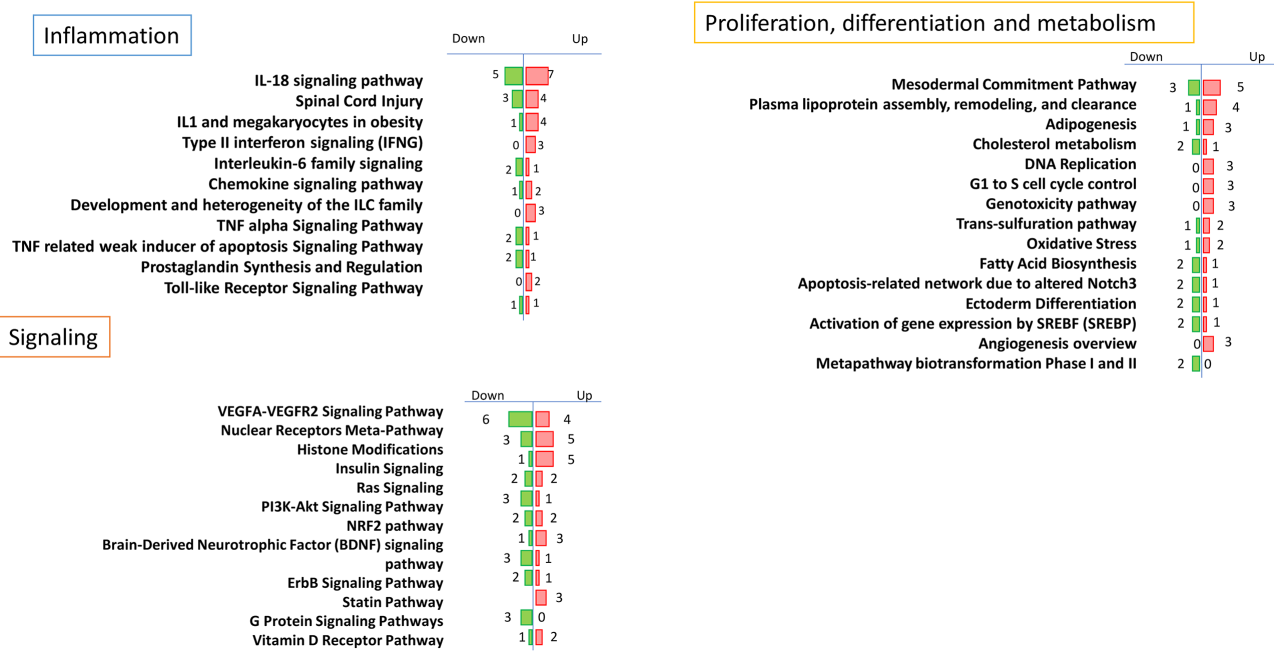

FIGURE 3 | Per pathways analysis of Subset A. Analysis of 407 transcripts differentially modulated only in Diffuse Gastric Cancer vs Healthy Gastric Mucosa: identification of several pathways that can be grouped in three principal clusters: Proliferation, differentiation and metabolism, Inflammation and Signaling

TABLE 2 | Principal pathways of Proliferation, differentiation and metabolism Cluster for the subset A.

Proliferation, differentiation and metabolism
Mesodermal Commitment Pathway
Plasma lipoprotein assembly, remodeling, and clearance
Adipogenesis
Cholesterol metabolism (includes both Bloch and Kandutsch-Russell pathways)
DNA Replication
G1 to S cell cycle control
Genotoxicity pathway
Trans-sulfuration pathway
Oxidative Stress
Fatty Acid Biosynthesis
Apoptosis-related network due to altered Notch3
Ectoderm Differentiation
G1 to S cell cycle control
Genotoxicity pathway
Trans-sulfuration pathway
Oxidative Stress

\begin{tabular}{ll}
\multicolumn{1}{c}{ Upregulated genes } & Downregulated gen \\
KLF5, ASCC3, HNF4A, HPRT1, HMGA2 & ATP8B2, PBX1, ARID \\
APOC2, APOE, APOC1, NCEH1 & VLDLR \\
KLF5, TRIB3, LMNA & CNTFR \\
FASN & TM7SF2, CYP27A1 \\
CDC7, POLA2, POLE2 & \\
POLE2, CREB3L1, POLA2 & \\
HIST1H2BI, HIST1H2BM, HIST1H3D & \\
GCLM, DNMT1 & GGT6 \\
HMOX1, NOX4 & MT1X \\
FASN & ECHDC2, ACACB \\
APOE & TRAF1, NGFRAP1 \\
STC1 & CCL2, CTNND2 \\
POLE2, CREB3L1, POLA2 & \\
HIST1H2BI, HIST1H2BM, HIST1H3D & \\
GCLM, DNMT1 & GGT6 \\
HMOX1, NOX4 & MT1X
\end{tabular}


Conversely, we found a downregulation of VLDLR, whose genetic or epigenetic silencing contributes to gastric carcinogenesis (70), CYP27A1, which induces $\mathrm{T}$ cell dysfunction, thus promoting breast cancer progression (71) and CCL2, downregulated in diffuse gastric cancer primarily in advanced stages (72).

Although to a lesser extent, we also found a modulation of genes involved in inflammatory and signaling pathways (Supplementary Tables 4, 5). Interestingly, we found an upregulation of inflammatory genes including IL-18, marker of TAMs (Tumor associated macrophages) probably correlated with tumor invasion ability (73), IFN- $\gamma$, that promotes gastric tumorigenesis in mice and regulates the expression of PD1 via JACK/STAT signaling $(74,75)$, CCL22, that promotes EMT activating PI3K/AKT pathway and is correlated with peritoneal metastasis in gastric cancer patients $(76,77)$, and CCL28, molecular target of $\mathrm{Wnt} / \beta$-cathenin overexpressed in gastric cancer (78). Furthermore, we found an overexpression of MMP-9, that promotes tumor invasion and is associated with poor prognosis in gastric cancer (79), ANXA1 and ANXA4, overexpressed in gastric cancer and associated with proliferation $(80,81)$, AREG, that promotes malignant progression in several types of cancer [85]. Among the downregulated genes we found ADAMTS1, a metalloprotease with anti-angiogenic activity expressed at low levels in primary tumors (82). Moreover, the 3 most overexpressed specific genes in diffuse gastric cancer resulted REG4, LCN2 and CEACAM5 (fold change of 16.97, 7.63 and 6.34 respectively): REG4 is generally overexpressed in gastric cancer and promotes peritoneal metastasis, increasing adhesion ability of gastric cancer cells (83); LCN2 is overexpressed in gastric cancer mucosa infected with $H$. pylori and correlated with invasion, metastasis and poor prognosis of gastric cancer (84, 85); the expression of CEACAM5 is associated with tumor progression, invasion and migration and it is considered an independent prognostic predictor in patients with advanced stages of gastric cancer $(86,87)$. Conversely the most downregulated gene in diffuse gastric cancer subset is REG1A (fold change of -7.47), a tumor suppressor that, when overexpressed, reduces invasion and promotes apoptosis of gastric cancer cells, and that is typically downregulated in gastric cancer patients $(88,89)$.

\section{Transcriptome Analysis: Identification of Markers Specific for Intestinal Gastric Cancer}

The analysis of intestinal gastric cancer subset indicated as subset B (Figure 4), immediately showed a stronger inflammatory component, likely due to its greater association with $H$. pylori infection. As shown in Table 3, the per pathway analysis of inflammatory cluster indicates a great modulation of genes involved in chemotaxis, inflammation, Innate and adaptative immunity (Table 3). First, we found a strong modulation of IL18 signaling pathway with an overexpression of several genes including CCL4, whose increased expression in stromal compartment is associated with Intestinal gastric cancer (43), FN1, considered a prognostic biomarker in gastric cancer associated with a poor prognosis (90), and PTGS2, encoding for COX2 gene with a key role in the generation of the inflammatory microenvironment in tumor tissues inducing the expression of several cytokines and chemokines, which play tumor-promoting role $(45,91)$. In this pathway, we have also found a downregulation of CCL19, a tumor suppressor that reduces proliferation, migration and invasion in gastric cancer (92), and NR0B2, whose downregulation in renal carcinoma is associated with development and progression of cancer (93). Moreover the, Intestinal gastric cancer group is characterized by a modulation of chemokine signaling pathway, in which we found an increased

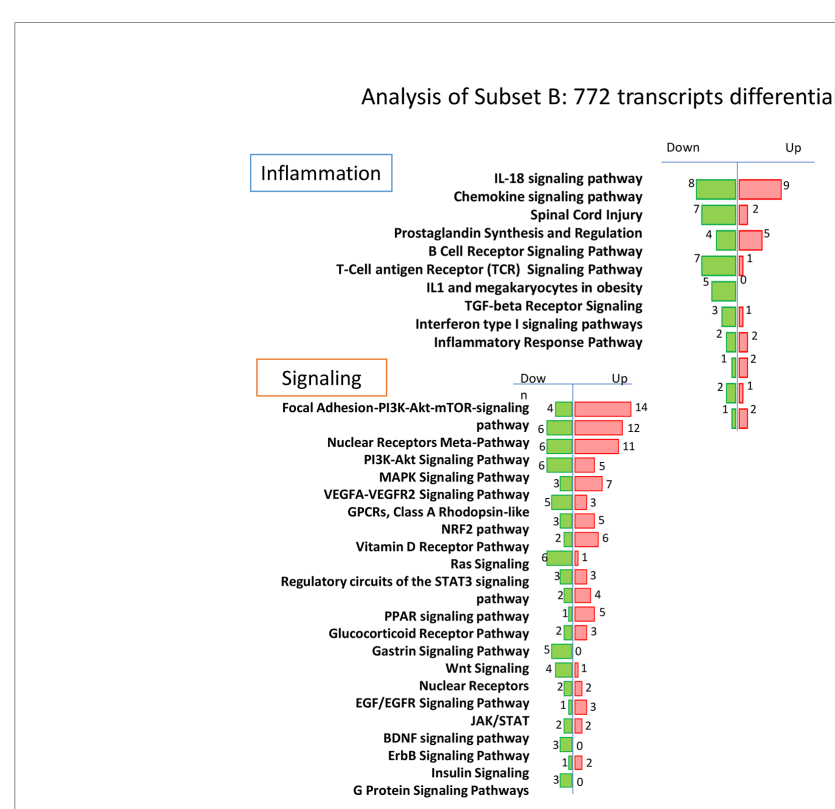

modulated only in Intestinal GC vs Healthy Gastric Mucosa 
TABLE 3 | Principal pathways of Inflammation Cluster for the subset B.

\begin{tabular}{|c|c|c|}
\hline Inflammation & Upregulated genes & Downregulated genes \\
\hline IL-18 signaling pathway & $\begin{array}{l}\text { NCF2, CCL4, PLOD3, BID, HCAR2, FN1, PTGS2, TGM2, } \\
\text { ULBP2 }\end{array}$ & $\begin{array}{l}\text { FOXN3, KLF2, PRKCB, CCL19, DES, ACTA2, NROB2, } \\
\text { SPON1 }\end{array}$ \\
\hline Chemokine signaling pathway & CXCR2, CCL4 & $\begin{array}{l}\text { CCL19, CCL11, CXCL14, VAV3, PRKCB, PRKACB, } \\
\text { AKT3 }\end{array}$ \\
\hline Spinal Cord Injury & E2F1, RTN4R, LILRB3, PTGS2, GJA1 & SLIT2, SLIT3, RGMA, VIM \\
\hline Prostaglandin Synthesis and Regulation & PTGS2 & $\begin{array}{l}\text { PTGFR, PTGER1, HPGD, HPGDS, AKR1C3, AKR1C1, } \\
\text { AKR1C2 }\end{array}$ \\
\hline B Cell Receptor Signaling Pathway & & CD79B, CD79A, BLNK, BLK, CR2 \\
\hline T-Cell antigen Receptor (TCR) Signaling & RIPK2 & GRAP2, VAV3, VIM \\
\hline \multicolumn{3}{|l|}{ Pathway } \\
\hline IL1 and megakaryocytes in obesity & TIMP1, S100A9 & SELENBP1, FCER1A \\
\hline TGF-beta Receptor Signaling & BAMBI, SERPINE1 & $\mathrm{BMP} 4$ \\
\hline Interferon type I signaling pathways & socs3 & PDCD4, PTPRC \\
\hline Inflammatory Response Pathway & FN1, LAMA5 & CD40LG \\
\hline
\end{tabular}

expression of CXCR2, the IL8 receptor, associated with poor prognosis and metastasis (94), and conversely a downregulation of CCL19, that suppresses proliferation, migration and invasion of gastric cancer cells (92), and CXCL14, whose promoter hypermethylation is associated with depth of penetration and prognosis of gastric cancer (95).

Among inflammatory pathways, we found also an overexpression of several genes identified as diagnostic or prognostic markers of gastric cancer including E2F1, that induces upregulation of lncRNA HCG18 thus stimulating proliferation and migration of gastric cancer (96), TIMP1, a key gene in the development of gastric cancer recognized as a potential prognostic marker when co-expressed with MMP-7 (97, 98), S100A9, a diagnostic and prognostic biomarker in gastric cancer $(99,100)$, and SERPINE1, highly expressed and significantly related to a poor prognosis of gastric adenocarcinoma (90). Interestingly, also LAMA5 that promotes colorectal liver metastasis growth, resulted upregulated in intestinal gastric cancer (101).

The per pathway analysis of Signaling cluster in intestinal gastric cancer revealed a higher modulation of several signaling pathways such as PI3K-AKT-mTOR, MAPK, RAS, JAK/STAT, NF-kB, VEGF (Table 4).

TABLE 4 | Principal pathways of Signaling Cluster for the subset B.

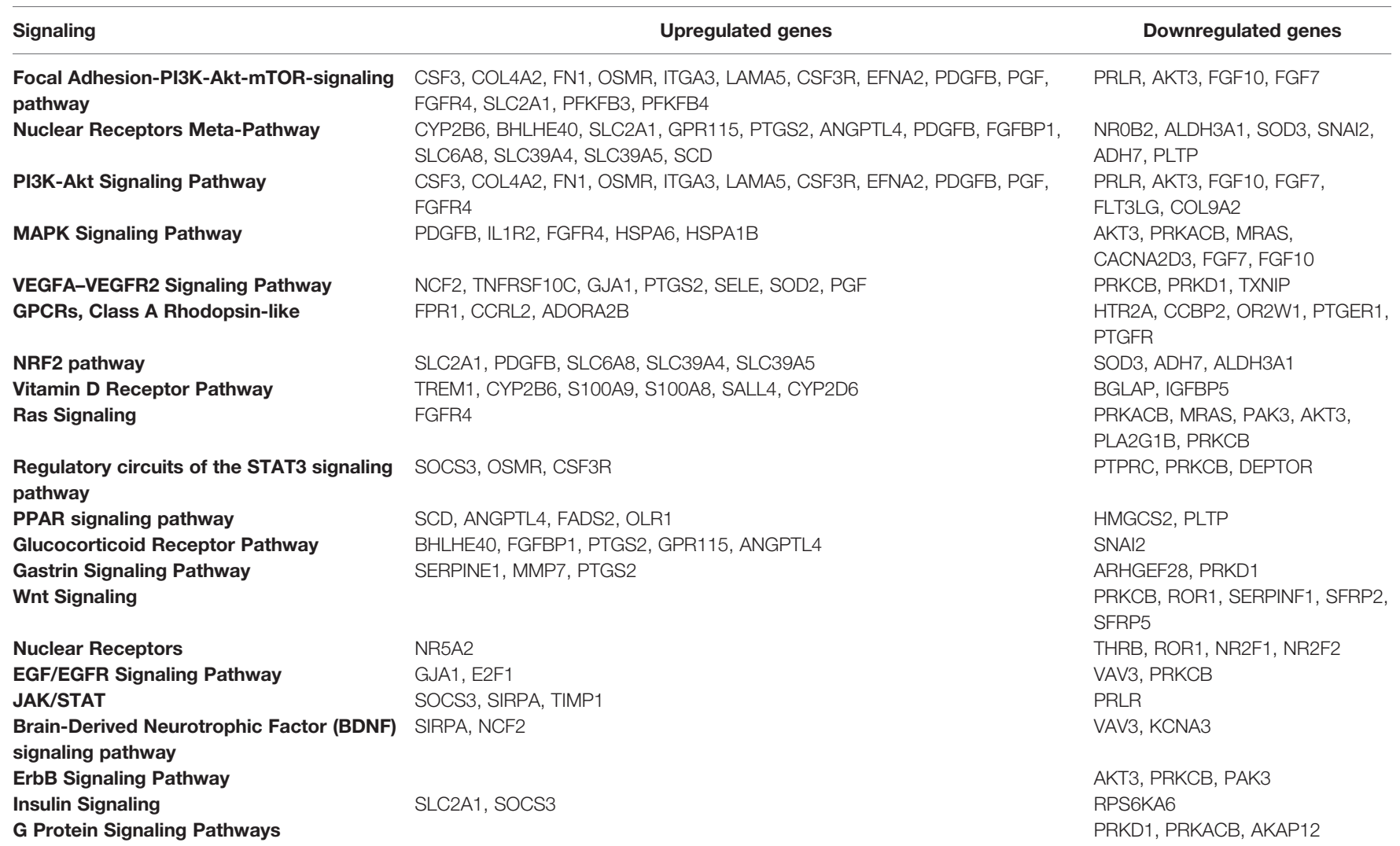


The pathway most modulated resulted the Focal Adhesion-PI3KAKT-mTOR-signaling pathway with 14 upregulated genes and 4 downregulated genes. In particular we found an overexpression of OSMR, the receptor of Oncostatin $\mathrm{M}$ which promotes gastric cancer growth and metastasis (102), ITGA3, which promotes peritoneal metastasis and correlates with poor prognosis in patients with gastric cancer (103), EFNA2, one of the members of the ephrin family that are target of WNT/beta-catenin signaling implicated in the development of carcinogenesis (104), PDGFB, whose overexpression increases the growth, invasion, and angiogenesis of gastric carcinoma cells (105), FGFR4, that regulates proliferation and anti-apoptosis during gastric cancer progression (106), and SLC2A1, that induces tumor cell proliferation and metastasis in gastric Cancer when overexpressed (107).

Interestingly, among the other pathways we found an increased expression of OLR1, that facilitates metastasis of gastric cancer through driving EMT and PI3K/AKT/GSK3 $\beta$ activation (108), and MMP7, identified as prognostic marker in gastric cancer when coexpressed with TIMP1 (98). Conversely HMGCS2, identified as tumor suppressor with prognostic impact in prostate cancer, resulted downregulated also in intestinal gastric cancer subset (109).

The analysis of Proliferation, differentiation and metabolism Cluster (Supplementary Table 6) revealed among others, the overexpression of several genes involved in invasion and metastasis of gastric cancer including CXCR1, that promotes malignant behavior of gastric cancer cells in vitro and in vivo inducing AKT and ERK1/2 phosphorylation (110, 111), FPR2, that induces invasion and metastasis of gastric cancer cells and predicts the prognosis of patients acting as a novel prognostic marker (112), CARD14, involved in the progression from normal gastric epithelial to gastric cancer (113). Finally, we found also a decreased expression of CLDN11, whose silencing is associated with increased invasiveness of gastric cancer cells (114). Furthermore, the most upregulated genes specific for intestinal gastric cancer subset resulted OLFM4, involved in early gastric carcinogenesis and associated with prognostic significance in advanced stages (115), CDH17 and TFF3, specific markers of intestinal metaplasia gastric cancer patients (116), TRIM29, identified as oncogene in gastric cancer marker of lymph node metastasis $(117,118)$, and SYT8, a promising target for the detection, prediction, and treatment of peritoneal metastasis of gastric cancer (119). Conversely, among the transcripts more downregulated we found PSCA, whose reduced expression promotes gastric cancer proliferation and is related to poor prognosis (120), GKN2, which results downregulated in gastric cancer and when restored suppresses gastric tumorigenesis and cancer metastasis (121), and ALDH1A3, MLF1 and GREM1, all methylated at promoter level in gastric cancer (122).

\section{Functional Enrichment Analysis of Diffuse Gastric-Specific Genes and Intestinal-Specific Genes}

Finally, functional enrichment analysis was performed separately for gastric cancer histotype-specific genes, using DAVID tools (24) and the results were shown in Figure 5. For histotypespecific genes in diffuse gastric cancer tissues, functions including methylation, lipid metabolism (VLDL, Lipoprotein, Lipid Transport, Lipid metabolism, HDL), cell division and adhesion were significantly enriched (Figure 5). Conversely, the histotypespecific genes in intestinal gastric cancer samples were dramatically enriched in functions, including cell migration (cell membrane, extracellular matrix, metalloproteases, chemotaxis), vasculature development (angiogenesis, cell adhesion), apoptosis, but especially immune system regulation and inflammation (immunoglobulin domain, cytokine, innate immunity, cytokinecytokine receptors interaction, adaptative immunity, prostaglandin metabolism, B cell activation) (Figure 5).

Accordingly, these data confirmed that as described above intestinal histotype-specific genes were significantly enriched in biological processes such chemotaxis, inflammation, Innate and adaptative immunity, cellular adhesion, angiogenesis and modulation of several signaling pathways, such as PI3K-AKTmTOR, MAPK, ERK1/2, RAS, JAK/STAT, NF-kB, VEGF, involved in their regulation.

\section{Identification of Histotype-Specific Genes}

10 In order to refine the analysis, the selection criteria were strengthened with a threshold of FDR $\leq 0.1$ and fold-change $\geq 3$ applied. The stringent criteria generated a list of seven upregulated and zero downregulated transcripts in diffuse gastric cancer compared with healthy mucosa, whereas we found 14 upregulated transcripts and 11 downregulated transcripts in intestinal gastric cancer that met these criteria (Figures 6A, B).

Interestingly, we found nine of these genes selected by using the stringent criteria, when we analyzed the Differential Expressed Genes (DEGs) between Intestinal gastric cancer and Diffuse gastric cancer samples (Figure 6C). In particular, genes encoding for $\mathrm{N}$-formyl peptide receptor 2 (FPR2), Caspase recruitment domain-containing protein 1 (CARD14), C-X-C Motif Chemokine Receptor 2 (CXCR2), Ephrin A2 (EFNA2), C-X-C Motif Chemokine Receptor 1 (CXCR1), Aquaporin-9 (AQP9) and Thyroid Hormone Receptor Interactor 13 (TRIP13) resulted overexpressed in Intestinal Gastric cancer. Conversely, the expression of genes encoding for Ghrelin (GHRL) and Kallikrein Related Peptidase 11 (KLK11) was decreased in intestinal gastric cancer compared with diffuse histotype (Figure 6C). For these reasons, our results suggest that FPR2, CARD14, CXCR2, EFNA2, CXCR1, AQP9 TRIP13, along with GHRL and KLK11, could be used as promising biomarkers for gastric cancer diagnosis or prognostic evaluation.

\section{Clinical Results}

The 4-year overall survival (4Y-OS) of the study population is $52 \%$ (Figure 7A). The Kaplan-Meier survival curve showed that intestinal group presented a $4 \mathrm{Y}-0 \mathrm{~S}$ of $80 \%$. Conversely, diffuse group has revealed a worse prognosis with only $25 \%$ of patients alive after four years from surgery resection (Figure 7B). The difference was statistically significant.

According to the univariate analysis, performed as described in material and method section, the Intestinal group there was no clinical factor impacting the overall survival, whereas in the diffuse group, male sex and High N/L ratio worsen patients' prognosis (Figures 7C-F). In particular, in diffuse sub set females seems to have a better survival (4Y-OS: 40\%) compared to males (4Y-OS: $0 \%$ ) (Figure $7 \mathrm{C}$ ). According to the median value of N/L ratio, 


\section{Functional enrichment results of Histotype-specific genes.}

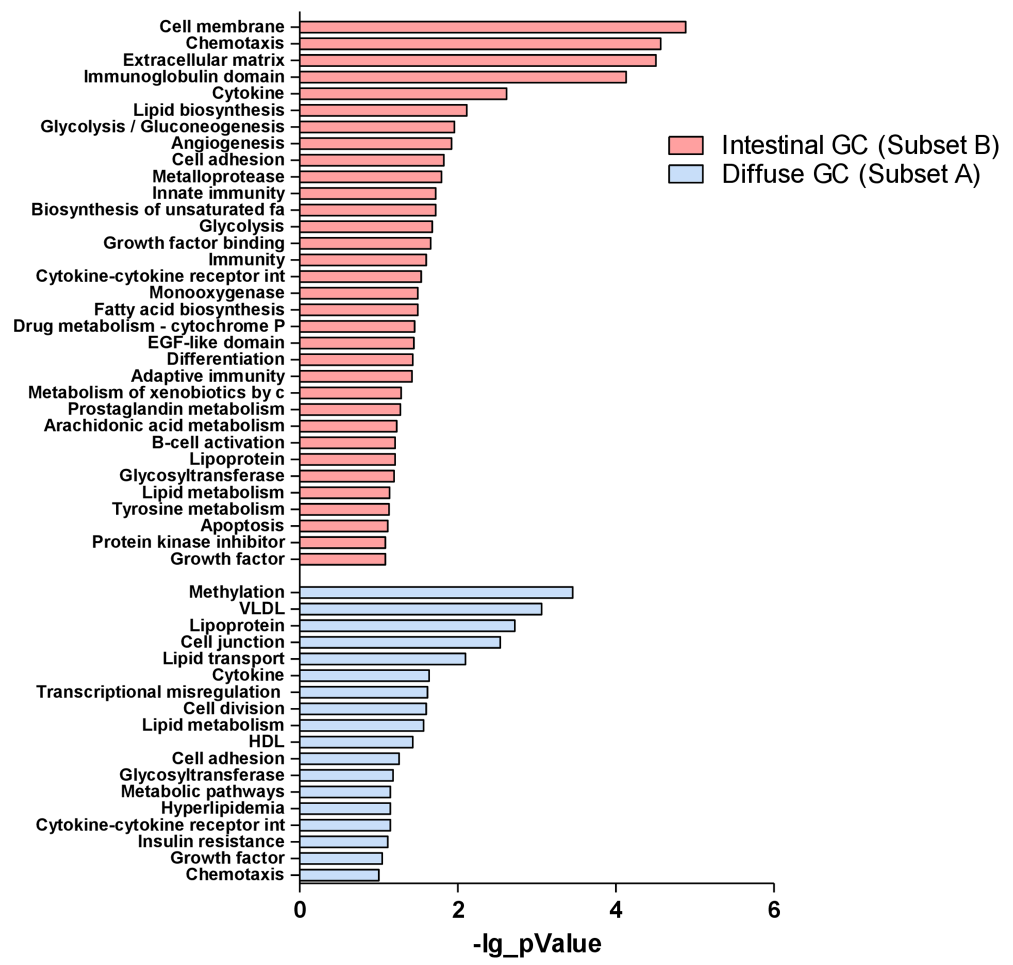

FIGURE 5 | Functional enrichment analysis of Histotype-specific genes. Functional enrichment results of diffuse gastric-specific genes and intestinal-specific genes performed separately using DAVID tools.

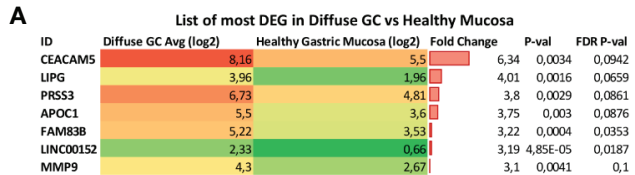

B

List of most DEG in Intestinal GC vs Healthy Mucosa
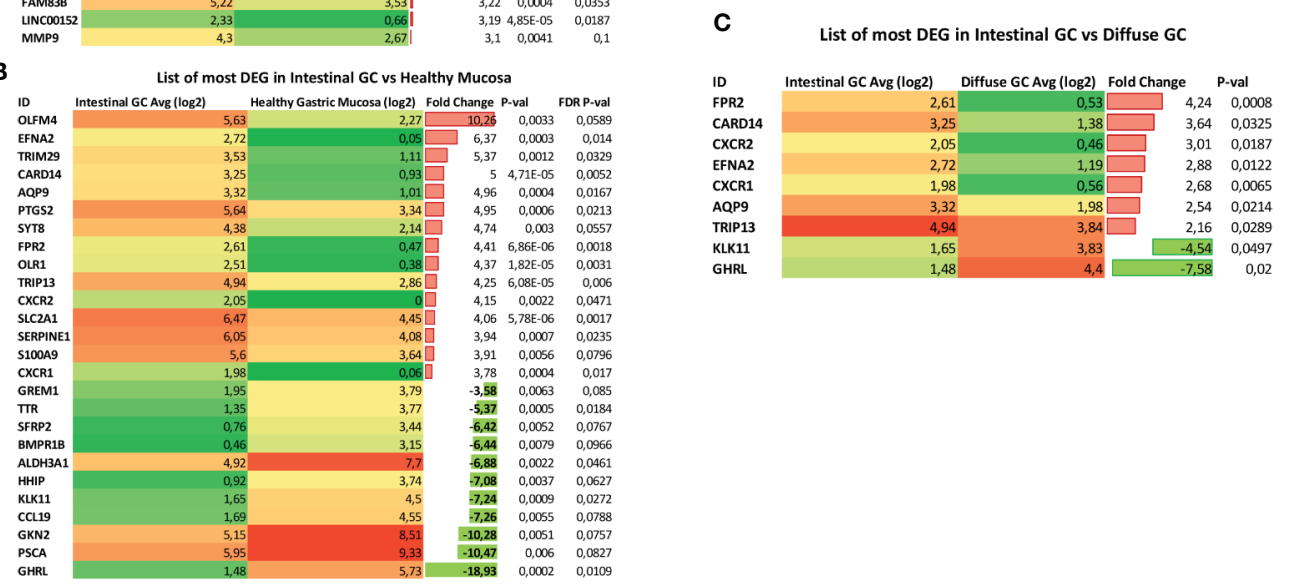

FIGURE 6 | Identification of Histotype-specific genes. List of Differential Expressed Genes (DEGs) obtained using stringent criteria (threshold of FDR $\leq 0.1$ and fold-change $\geq 3$ applied) in (A) diffuse gastric cancer and (B) intestinal gastric cancer compared with healthy mucosa. (C) List of DEGs selected by using the stringent criteria between Intestinal gastric cancer and Diffuse gastric cancer samples. 


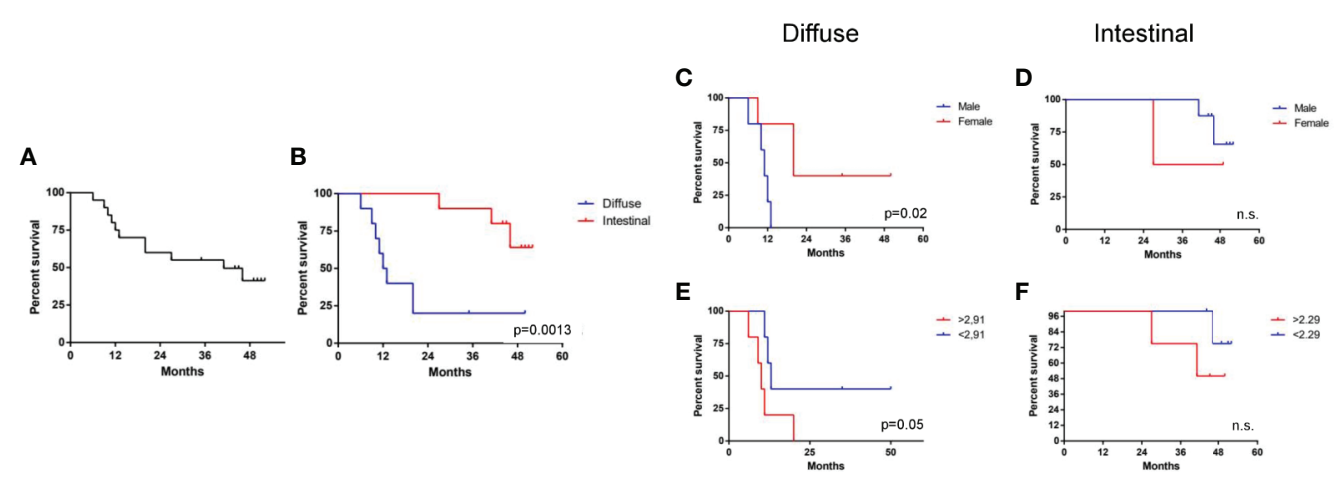

FIGURE 7 | Clinical results. (A) 4-year overall survival (4Y-OS) of the study population. (B) Kaplan-Meier survival curve showing the 4Y-OS of intestinal and diffuse group ( $\mathrm{p}<0.05$ ). Analysis of $4 \mathrm{Y}$-OS performed as described in material and method section according sex (C, D) or N/L ratio status (E, $\mathbf{F})$ in diffuse and intestinal groups $(p<0.05)$.

patients were dichotomized into two subgroups. In the diffuse type, the survival was lower in the N/L higher group (40\% vs $0 \%$ ), as shown in Figure 7E, in a statistically significant way. This was not confirmed in the intestinal subgroup (Figure 7F). In the diffuse group we eventually considered sex and N/L ratio status in multivariate analysis, but none of these factors turned out to be statistically independent.

At the end of our analysis, we evaluated the impact of genes' expression in overall survival. For this purpose, patients were dichotomized into two groups according to the median value of expression each gene (Figure $\mathbf{8 A}$ ). In the intestinal group only AQP9 gene expression showed an impact in patient survival: patients having a high AQP9 expression show a significant worse prognosis compared to patients with low expression $(31.5 \%$ vs $100 \%$ $4 \mathrm{Y}$-OS) (Figure 8B). In the diffuse group the expression of two genes, CARD14 and CXCR2, revealed an impact in patient survival. Despite the lower expression of these genes in diffuse group compared to intestinal group, the higher expression of CARD14 or CXCR2 was significantly associated with a worse prognosis in patients of diffuse subset (Figures 8C, D). In particular, patients with a higher expression of CARD14 or CXCR2 show a 4Y-OS of $0 \%$ compared to patients having a lower expression of these genes, in which the $4 \mathrm{Y}$-OS was of 42 and $40 \%$ respectively (Figures 8C, D). Furthermore, we considered both CARD14 and CXCR2 expression in multivariate analysis, and we found that in particular the CXCR2 expression resulted a statistically independent factor (Table 5).

\section{DISCUSSION}

In the present study we report an integrative approach combining the transcriptome sequencing (RNA-seq) and clinical-pathological phenotypes to a series of gastric cancer

A
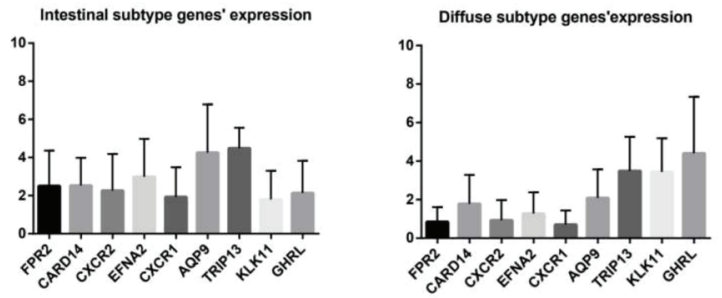

B

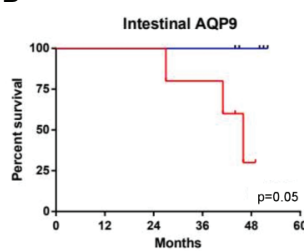

C

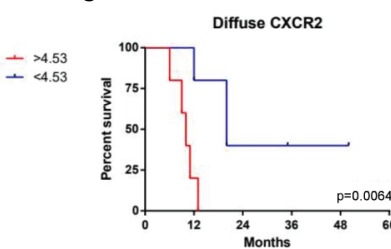

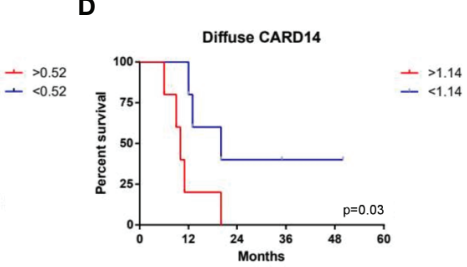

FIGURE 8 | Impact of gene expression in overall survival. (A) Patients were dichotomized into two groups according to the median value of expression each gene. (B) Impact of AQP9 gene expression on patient survival in the intestinal group. Impact of (C) CXCR2 and (D) CARD14 on patient survival in the diffuse group ( $p<0.05$ ). 
TABLE 5 | Multivariate analysis of gene expression for the diffuse subset.

\begin{tabular}{|c|c|c|c|c|c|c|}
\hline Covariate & Regression Coef. & SE & Regression coef./SE & $\mathbf{P}$ & $\mathbf{R R}$ & $95 \% \mathrm{Cl}$ RR \\
\hline CARD 14 & 1.3882 & 0.9045 & 2.3556 & 0.128 & 4.0075 & 0.869-23.3795 \\
\hline CXCR2 & 2.5435 & 1.2094 & 4.4228 & 0.0355 & 12.7244 & $1.2033-134.5504$ \\
\hline
\end{tabular}

recorded in a single center in Italy (123). The histopathological classifications by Lauren and the WHO remain widely used for the therapeutic decisional process (9). According to the Lauren classification, gastric cancers are subdivided into two major histological subtypes, namely intestinal type and diffuse type adenocarcinoma. Both the intestinal and the diffuse types have been associated with chronic gastritis and $H$. pylori infection, that represents the main cause of gastric cancer, however, the histological changes leading to intestinal type are better characterized (124), suggesting that the later could be considered the end-result of an inflammatory multistep process that starts with $H$. pylori infection and progresses to chronic gastritis, atrophic gastritis and finally to intestinal metaplasia and dysplasia $(7,124)$. Conversely, the development cascade for diffuse gastric cancer type, which convey a worst prognosis, is less defined. Despite the Lauren classification has been proposed more than half a century ago it maintains several advantages in term of easy handling and prognostic significance (125). Therefore, a more detailed knowledge of the molecular subsets of two pathology entities described by Lauren may lead to a newer approach to gastric cancer tailored treatment (126).

In this study we provide the results of in deep characterization of the transcriptome patterns from 12 diffuse and 12 intestinal gastric cancer patients using high-throughput sequencing technology. While a limitation of the study was the inclusion of only 24 patients, we have identified 885 transcripts differentially expressed in comparison to non-neoplastic tissue by both the diffuse and intestinal gastric cancer, that were considered to represent a group of recurrently deregulated genes potentially associated with tumorigenesis. As described in result section we found in this subset of transcripts a modulation of cell cycle regulators including, several genes involved in Epithelial to Mesenchymal Transition, chemokine and cytokine signaling pathways with an upregulation of genes such as CCL3, CCL15 (43), CCL20 (44), CXCLs family (45-50), IL-1 $\beta$, IL-11 and IL-8 (51-53). Of interest, some of these genes, including CXCR4 and PI3K-AKT, were also found to be poor outcome predictors in a subgroup of diffuse gastric cancer patients by proteomic analysis, further confirming the results of our transcriptome analysis (127).

Surprisingly, the analysis of diffuse gastric cancer subset revealed in addition to a modulation of immune and proliferation pathways, also an upregulation of genes involved in proliferation and lipid metabolism such as HNF4A (65), APOC1 (66),, APOE $(67,68)$, , FASN (69), while the expression of VLDLR (70) and CCL2 (72), were downregulated.

The analysis of intestinal gastric cancer subset shows a strong inflammatory component, likely due to its close association with $H$. pylori infection, with a robust modulation of genes involved in chemotaxis, inflammation and innate and adaptive immunity. Moreover, the per pathway analysis revealed a higher modulation of several signaling pathways including PI3K-AKT-mTOR, MAPK, RAS, JAK/STAT, NF-kB, VEGF (127). Of relevance the PI3K-AKT pathway has been extensively validated as a potential drug target in the diffuse type of gastric cancer by proteomic analysis, and a higher protein expression of these biomarkers associate with worse patient's outcome (127).

These data were confirmed also by the functional enrichment analysis performed using DAVID tool. We found that the diffuse gastric cancer tissues were enriched for functions including methylation, lipid metabolism cell division and adhesion, whereas the intestinal gastric cancer group was dramatically enriched for genes involved in cell migration, vasculature development apoptosis, immune system regulation and inflammation.

The clinical analysis of our study population first confirmed that patients affected by diffuse type adenocarcinoma showed a worse prognosis with only $25 \%$ of patients' survival after four years from surgical resection. None of the clinical factors investigated (Table 1) had any impact on intestinal group prognosis, while gender and preoperative inflammation status impacted on the survival of patients with diffuse gastric cancers, although at the multivariate analyses none of the clinical parameters maintained a statistical significance.

To better characterize the diffuse and intestinal gastric cancer transcriptome profile, we have strengthened the selection criteria for the analysis of differentially modulated genes (DEGs). Therefore, we have selected nine genes differentially modulated between the intestinal and diffuse gastric cancer samples: FPR2, CARD14, CXCR2, EFNA2, CXCR1, AQP9, TRIP13, GHRL and KLK11, to be used as differentially expressed biomarkers for gastric cancers. In following this approach, we have first investigated whether the nine selected genes impact on overall patients' survival. The results of this subset analysis demonstrated that in the intestinal group only the expression of AQP9 gene exerted a significant impact in patient survival. AQP9, a member of the aquaporin family, is involved in development of several tumors, promoting the proliferation, migration and invasion of tumor cells (128). Previous studies have shown that AQP9 induces the growth and the migration of prostate cancer (129) and astrocytoma cells (130). Conversely, AQP9 might inhibit the invasion of liver cancer cells and the proliferation of xenograft tumors (131), and also activates RAS signal and sensitize tumor cells to chemotherapy in colorectal cancer (132). AQP9 had significant association with various immune infiltrating cells including CD8+ and CD4+ T cells, neutrophils, tumor associated macrophages (TAMs) and dendritic cells (DCs) $(133,134)$. However, high AQP9 expression was significantly correlated with worse prognosis in breast (135), colon and lung cancers (136), while predicted better prognosis in gastric cancer both in diffuse and intestinal gastric cancer (137). Therefore, we can suppose that our results showing 
a worse prognosis for patients with high levels of AQP9 in intestinal gastric cancer subset, may be due to the presence of a stronger immune and inflammatory component. Moreover, it was been shown that gene markers of M2 macrophages were moderately to very strongly correlated with AQP9 expression (138), suggesting that AQP9 might be involved in the polarization of TAMs and in the immunosuppression in cancer.

In the diffuse gastric cancer group, both CARD14 and CXCR2 expression, revealed an impact in patient survival. In this subset, the higher expression of CARD14 or CXCR2 was significantly associated with a worse patient prognosis. Importantly, the multivariate analysis revealed that the CXCR2 expression resulted a statistically independent factor.

CARD14, is a member of the Caspase recruitment domain family of proteins, which play an important role in immune and inflammatory response, and cell survival and proliferation. It is strongly expressed in the epidermal keratinocyte of the skin and is involved in inflammatory disorders of the human skin, such as psoriasis $(139,140)$. CARD14 isoforms are expressed in several hematopoietic cells and tissues such as bronchus, cervix, colon and lung as well as cancer cell lines derived from these tissues (141, 142). In particular, it was shown that CARD14 resulted overexpressed in breast cancer cell lines, and its knockdown led to decreased breast cancer cell proliferation and migration ability, accompanied by the induction of cell death through NF- $\mathrm{kB}$ (143).

CXCR2, is a potent pro-tumorigenic chemokine receptor that can induce inflammation in the tumor microenvironment by mediating the recruitment of different stromal cells and thus promoting the progression of cancer cells (144). CXCR2-targeted therapy has shown previously promising results in several solid tumors, including breast cancer (145), pancreatic cancer (146), and rhabdomyosarcoma (147). More recently, its expression has been associated with the prognosis of patients with gastric cancer (48). CXCR2 ligands, produced by TAM, significantly promote proliferation and migration of gastric cancer cells through activating a CXCR2/STAT3 feed-forward loop (148). Gastric cancer cells in turn, secrete TNF- $\alpha$ to induce the release of CXCR2 ligands from macrophages (48). Furthermore, CXCR2 along with CXCR4 overexpression, was associated with more advanced tumor stages and poorer survival in gastric cancer patients (94). CXCR4 and CXCR2 activate NF- $\mathrm{KB}$ and STAT3 signaling, while NF- $\mathrm{Bp} 65$ can then transcriptionally activate CXCR4 and STAT3 can activate CXCR2 expression (94). It was been shown that this crosstalk between CXCR4 and CXCR2 contributed to EMT, migration and invasion of gastric cancer. Conversely, the inhibition of CXCR2 pathway in gastric cancer cells suppressed migration and metastasis of gastric cancer both in vitro and in vivo (48). Therefore, the interaction between CXCR2 and tumor microenvironment results of critical importance for tumor progression (149). Recent studies have been demonstrated that the blockade of the receptor with specific inhibitors (150), as well as the inhibition of the recruitment of immune cells via the CXCL1-CXCR2 axis (144), appear a promising therapy for gastric cancer primarily for diffuse subtype (127).

In summary our analysis detected seven genes up regulated in the Intestinal type and two genes down regulated when compared to the healthy mucosa, with AQP9 expression influencing also patients' prognosis. In the diffuse type, with an $a b$-initio worse prognosis, we were able to detect two genes, CARD14 and CXCR2, impacting prognosis. In particular CXCR2 seems to play a key role, resulting the only factor independently impacting overall survival.

The present study suggests that targeting AQP9 and CXCR2 may represent a novel strategy for gastric cancer therapy, in intestinal and diffuse patients respectively. However, further studies will be needed to confirm the role of these genes as therapeutic targets and biomarkers in gastric cancer.

\section{DATA AVAILABILITY STATEMENT}

The datasets presented in this study can be found in online repositories. The names of the repository/repositories and accession number(s) can be found below: https://data. mendeley.com/, 10.17632/d3ykf83tyv.1.

\section{ETHICS STATEMENT}

Permission to collect post-surgical samples was granted to SF by the ethical committee of Umbria (CEAS). Permit FI00001, n. 2266/2014 granted on February 19, 2014. The patients/ participants provided their written informed consent to participate in this study.

\section{AUTHOR CONTRIBUTIONS}

SF, AD, LG, EM, and AC contributed to conception and design of the study. VS and $\mathrm{AZ}$ provided research funding. $\mathrm{AD}, \mathrm{LG}$, and $\mathrm{EM}$ provided human samples. AC, EM, SM, and MB performed the data analysis. AC, EM, SM, and MB performed the statistical analysis. LG, $\mathrm{EM}, \mathrm{AZ}, \mathrm{VS}, \mathrm{SF}, \mathrm{ED}$, and AC wrote the manuscript. All authors contributed to the article and approved the submitted version.

\section{FUNDING}

This work was supported by a grant from Regione CampaniaPOR Campania FESR 2014/2020 “Combattere la resistenza tumorale: piattaforma integrata multidisciplinare per un approccio tecnologico innovativo alle oncoterapie-Campania Oncoterapie" (Project N. B61G18000470007).

\section{ACKNOWLEDGMENTS}

This manuscript has been released as a PrePrint (bioRxiv https:// doi.org/10.1101/2021.02.02.429357).

\section{SUPPLEMENTARY MATERIAL}

The Supplementary Material for this article can be found online at: https://www.frontiersin.org/articles/10.3389/fonc.2021.663771/ full\#supplementary-material 


\section{REFERENCES}

1. Rawla P, Barsouk A. Epidemiology of Gastric Cancer: Global Trends, Risk Factors and Prevention. Prz Gastroenterol (2019) 14(1):26-38. doi: 10.5114/ pg.2018.80001

2. Bray F, Ferlay J, Soerjomataram I, Siegel RL, Torre LA, Jemal A. Global Cancer Statistics 2018: GLOBOCAN Estimates of Incidence and Mortality Worldwide for 36 Cancers in 185 Countries. CA Cancer J Clin (2018) 68 (6):394-424. doi: 10.3322/caac.21492

3. Torre LA, Bray F, Siegel RL, Ferlay J, Lortet-Tieulent J, Jemal A. Global Cancer Statistics, 2012. CA Cancer J Clin (2015) 65(2):87-108. doi: 10.3322/ caac. 21262

4. Marano L, Polom K, Patriti A, Roviello G, Falco G, Stracqualursi A, et al. Surgical Management of Advanced Gastric Cancer: An Evolving Issue. Eur J Surg Oncol (2016) 42(1):18-27. doi: 10.1016/j.ejso.2015.10.016

5. Shiozaki H, Elimova E, Slack RS, Chen HC, Staerkel GA, Sneige N, et al. Prognosis of Gastric Adenocarcinoma Patients With Various Burdens of Peritoneal Metastases. J Surg Oncol (2016) 113(1):29-35. doi: 10.1002/ jso. 24087

6. Gill RS, Al-Adra DP, Nagendran J, Campbell S, Shi X, Haase E, et al. Treatment of Gastric Cancer With Peritoneal Carcinomatosis by Cytoreductive Surgery and HIPEC: A Systematic Review of Survival, Mortality, and Morbidity. J Surg Oncol (2011) 104(6):692-8. doi: 10.1002/ jso. 22017

7. Correa P. Human Gastric Carcinogenesis: A Multistep and Multifactorial Process-First American Cancer Society Award Lecture on Cancer Epidemiology and Prevention. Cancer Res (1992) 52(24):6735-40.

8. Lauren P. The Two Histological Main Types of Gastric Carcinoma: Diffuse and So-Called Intestinal-Type Carcinoma. An Attempt At a Histo-Clinical Classification. Acta Pathol Microbiol Scand (1965) 64:31-49. doi: 10.1111/ apm.1965.64.1.31

9. Berlth F, Bollschweiler E, Drebber U, Hoelscher AH, Moenig S. Pathohistological Classification Systems in Gastric Cancer: Diagnostic Relevance and Prognostic Value. World J Gastroenterol (2014) 20 (19):5679-84. doi: 10.3748/wjg.v20.i19.5679

10. Spoto CPE, Gullo I, Carneiro F, Montgomery EA, Brosens LAA. Hereditary Gastrointestinal Carcinomas and Their Precursors: An Algorithm for Genetic Testing. Semin Diagn Pathol (2018) 35(3):170-83. doi: 10.1053/ j.semdp.2018.01.004

11. Cristescu R, Lee J, Nebozhyn M, Kim KM, Ting JC, Wong SS, et al. Molecular Analysis of Gastric Cancer Identifies Subtypes Associated With Distinct Clinical Outcomes. Nat Med (2015) 21(5):449-56. doi: 10.1038/nm.3850

12. Sohn BH, Hwang JE, Jang HJ, Lee HS, Oh SC, Shim JJ, et al. Clinical Significance of Four Molecular Subtypes of Gastric Cancer Identified by The Cancer Genome Atlas Project. Clin Cancer Res (2017) 23:4441-9. doi: 10.1158/1078-0432.CCR-16-2211

13. Lei Z, Tan IB, Das K, Deng N, Zouridis H, Pattison S, et al. Identification of Molecular Subtypes of Gastric Cancer With Different Responses to PI3kinase Inhibitors and 5-Fluorouracil. Gastroenterology (2013) 145(3):55465. doi: 10.1053/j.gastro.2013.05.010

14. C. G. A. R. Network. Comprehensive Molecular Characterization of Gastric Adenocarcinoma. Nature (2014) 513(7517):202-9. doi: 10.1038/ nature 13480

15. Van Cutsem E, Bang YJ, Feng-Yi F, Xu JM, Lee KW, Jiao SC, et al. HER2 Screening Data From ToGA: Targeting HER2 in Gastric and Gastroesophageal Junction Cancer. Gastric Cancer (2015) 18(3):476-84. doi: 10.1007/s10120-014-0402-y

16. Marcus L, Lemery SJ, Keegan P, Pazdur R. Fda Approval Summary: Pembrolizumab for the Treatment of Microsatellite Instability-High Solid Tumors. Clin Cancer Res (2019) 25(13):3753-8. doi: 10.1158/10780432.CCR-18-4070

17. Ng HK, Roukos DH, Iacopetta B, Ku C-S. Next-Generation Sequencing in Cancer Epigenomics and Potential Clinical Applications. In: Next Generation Sequencing in Cancer Research. New York, NW: Springer (2013). doi: 10.1007/978-1-4614-7645-0_2

18. de Klerk E, den Dunnen JT, . 't Hoen PA. RNA Sequencing: From Tag-Based Profiling to Resolving Complete Transcript Structure. Cell Mol Life Sci (2014) 71(18):3537-51. doi: 10.1007/s00018-014-1637-9
19. Luo YH, Liang L, He RQ, Wen DY, Deng GF, Yang H, et al. RNASequencing Investigation Identifies an Effective Risk Score Generated by Three Novel lncRNAs for the Survival of Papillary Thyroid Cancer Patients. Oncotarget (2017) 8(43):74139-58. doi: 10.18632/oncotarget.18274

20. Han H, Jiang X. Disease Biomarker Query From RNA-Seq Data. Cancer Inform (2014) 13(Suppl 1):81-94. doi: 10.4137/CIN.S13876

21. Wang Y. Identifying Key Stage-Specific Genes and Transcription Factors for Gastric Cancer Based on RNA-sequencing Data. Med (Baltimore) (2017) 96 (4):e5691. doi: 10.1097/MD.0000000000005691

22. Kim YH, Liang H, Liu X, Lee JS, Cho JY, Cheong JH, et al. Ampko Modulation in Cancer Progression: Multilayer Integrative Analysis of the Whole Transcriptome in Asian Gastric Cancer. Cancer Res (2012) 72 (10):2512-21. doi: 10.1158/0008-5472.CAN-11-3870

23. Amin MB, Greene FL, Edge SB, Compton CC, Gershenwald JE, Brookland RK, et al. The Eighth Edition AJCC Cancer Staging Manual: Continuing to Build a Bridge From a Population-Based to a More "Personalized" Approach to Cancer Staging. CA Cancer J Clin (2017) 67(2):93-9. doi: 10.3322/caac.21388

24. Huang DW, Sherman BT, Lempicki RA. Systematic and Integrative Analysis of Large Gene Lists Using DAVID Bioinformatics Resources. Nat Protoc (2009) 4(1):44-57. doi: 10.1038/nprot.2008.211

25. Gao SY, Li J, Qu XY, Zhu N, Ji YB. Downregulation of Cdk1 and cyclinB1 Expression Contributes to Oridonin-Induced Cell Cycle Arrest At G2/M Phase and Growth Inhibition in SGC-7901 Gastric Cancer Cells. Asian Pac J Cancer Prev (2014) 15(15):6437-41. doi: 10.7314/apjcp.2014.15.15.6437

26. Xing X, Chen J, Chen M. Expression of CDC25 Phosphatases in Human Gastric Cancer. Dig Dis Sci (2008) 53(4):949-53. doi: 10.1007/s10620-0079964-4

27. Zhang HP, Li SY, Wang JP, Lin J. Clinical Significance and Biological Roles of Cyclins in Gastric Cancer. Onco Targets Ther (2018) 11:6673-85. doi: 10.2147/OTT.S171716

28. Shi Q, Wang W, Jia Z, Chen P, Ma K, Zhou C. ISL1, a Novel Regulator of CCNB1, CCNB2 and c-MYC Genes, Promotes Gastric Cancer Cell Proliferation and Tumor Growth. Oncotarget (2016) 7(24):36489-500. doi: 10.18632/oncotarget.9269

29. Manicum T, Ni F, Ye Y, Fan X, Chen BC. Prognostic Values of. Biosci Rep (2018) 38(6):BSR20181264. doi: 10.1042/BSR20181264

30. Feng Y, Shi C, Wang D, Wang X, Chen Z. Integrated Analysis of DNA Copy Number Changes and Gene Expression Identifies Key Genes in Gastric Cancer. J Comput Biol (2020) 27(6):877-87. doi: 10.1089/cmb.2019.0149

31. Jin J, Shen X, Chen L, Bao LW, Zhu LM. TMPRSS4 Promotes Invasiveness of Human Gastric Cancer Cells Through Activation of NF- $\mathrm{kb} / \mathrm{MMP}-9$ Signaling. BioMed Pharmacother (2016) 77:30-6. doi: 10.1016/j.biopha.2015.11.002

32. Eftang LL, Esbensen Y, Tannæs TM, Blom GP, Bukholm IR, Bukholm G. Up-Regulation of CLDN1 in Gastric Cancer is Correlated With Reduced Survival. BMC Cancer (2013) 13:586. doi: 10.1186/1471-2407-13-586

33. Jung H, Jun KH, Jung JH, Chin HM, Park WB. The Expression of claudin-1, claudin-2, claudin-3, and Claudin-4 in Gastric Cancer Tissue. J Surg Res (2011) 167(2):e185-91. doi: 10.1016/j.jss.2010.02.010

34. Wu Z, Shi J, Song Y, Zhao J, Sun J, Chen X, et al. Claudin-7 (CLDN7) is Overexpressed in Gastric Cancer and Promotes Gastric Cancer Cell Proliferation, Invasion and Maintains Mesenchymal State. Neoplasma (2018) 65(3):349-59. doi: 10.4149/neo_2018_170320N200

35. Dong J, Wang R, Ren G, Li X, Wang J, Sun Y, et al. Hmga2-Foxl2 Axis Regulates Metastases and Epithelial-to-Mesenchymal Transition of Chemoresistant Gastric Cancer. Clin Cancer Res (2017) 23(13):3461-73. doi: 10.1158/1078-0432.CCR-16-2180

36. Yamamoto H, Kitadai Y, Oue N, Ohdan H, Yasui W, Kikuchi A. Laminin Gamma2 Mediates Wnt5a-induced Invasion of Gastric Cancer Cells. Gastroenterology (2009) 137(1):242-52.e1-6. doi: 10.1053/j.gastro. 2009.02.003

37. Zhou Y, Li G, Wu J, Zhang Z, Wu Z, Fan P, et al. Clinicopathological Significance of E-cadherin, VEGF, and MMPs in Gastric Cancer. Tumour Biol (2010) 31(6):549-58. doi: 10.1007/s13277-010-0068-y

38. Xu J, E C, Yao Y, Ren S, Wang G, Jin H. Matrix Metalloproteinase Expression and Molecular Interaction Network Analysis in Gastric Cancer. Oncol Lett (2016) 12(4):2403-8. doi: 10.3892/ol.2016.5013

39. Kwon CH, Moon HJ, Park HJ, Choi JH, Park DY. S100A8 and S100A9 Promotes Invasion and Migration Through p38 Mitogen-Activated Protein 
Kinase-Dependent NF- $\mathrm{kb}$ Activation in Gastric Cancer Cells. Mol Cells (2013) 35(3):226-34. doi: 10.1007/s10059-013-2269-x

40. Yu C, Chen J, Ma J, Zang L, Dong F, Sun J, et al. Identification of Key Genes and Signaling Pathways Associated With the Progression of Gastric Cancer. Pathol Oncol Res (2020) 26(3):1903-19. doi: 10.1007/s12253-019-00781-3

41. Zhang X, Yang JJ, Kim YS, Kim KY, Ahn WS, Yang S. An 8-Gene Signature, Including Methylated and Down-Regulated Glutathione Peroxidase 3, of Gastric Cancer. Int J Oncol (2010) 36(2):405-14. doi: 10.3892/ijo_00000513

42. Kim HJ, Kang TW, Haam K, Kim M, Kim SK, Kim SY, et al. Whole Genome MBD-seq and RRBS Analyses Reveal That Hypermethylation of Gastrointestinal Hormone Receptors is Associated With Gastric Carcinogenesis. Exp Mol Med (2018) 50(12):1-14. doi: 10.1038/s12276018-0179-x

43. Raja UM, Gopal G, Shirley S, Ramakrishnan AS, Rajkumar T. Immunohistochemical Expression and Localization of Cytokines/ Chemokines/Growth Factors in Gastric Cancer. Cytokine (2017) 89:82-90. doi: 10.1016/j.cyto.2016.08.032

44. Han G, Wu D, Yang Y, Li Z, Zhang J, Li C. Crkl Meditates CCL20/CCR6induced EMT in Gastric Cancer. Cytokine (2015) 76(2):163-9. doi: 10.1016/ j.cyto.2015.05.009

45. Echizen K, Hirose O, Maeda Y, Oshima M. Inflammation in Gastric Cancer: Interplay of the COX-2/prostaglandin E2 and Toll-like Receptor/MyD88 Pathways. Cancer Sci (2016) 107(4):391-7. doi: 10.1111/cas.12901

46. Takiguchi G, Nishita M, Kurita K, Kakeji Y, Minami Y. Wnt5a-Ror2 Signaling in Mesenchymal Stem Cells Promotes Proliferation of Gastric Cancer Cells by Activating CXCL16-CXCR6 Axis. Cancer Sci (2016) 107 (3):290-7. doi: $10.1111 /$ cas.12871

47. Yamamoto Y, Kuroda K, Sera T, Sugimoto A, Kushiyama S, Nishimura S, et al. The Clinicopathological Significance of the CXCR2 Ligands, CXCL1, Cxcl2, CXCL3, Cxcl5, CXCL6, CXCL7, and CXCL8 in Gastric Cancer. Anticancer Res (2019) 39(12):6645-52. doi: 10.21873/anticanres.13879

48. Zhou Z, Xia G, Xiang Z, Liu M, Wei Z, Yan J, et al. A C-X-C Chemokine Receptor Type 2-Dominated Cross-talk Between Tumor Cells and Macrophages Drives Gastric Cancer Metastasis. Clin Cancer Res (2019) 25 (11):3317-28. doi: 10.1158/1078-0432.CCR-18-3567

49. Cheng WL, Wang CS, Huang YH, Tsai MM, Liang Y, Lin KH. Overexpression of CXCL1 and its Receptor CXCR2 Promote Tumor Invasion in Gastric Cancer. Ann Oncol (2011) 22(10):2267-76. doi: 10.1093/annonc/mdq739

50. Ikeda T, Nishita M, Hoshi K, Honda T, Kakeji Y, Minami Y. Mesenchymal Stem Cell-Derived CXCL16 Promotes Progression of Gastric Cancer Cells by STAT3-mediated Expression of Ror1. Cancer Sci (2020) 111(4):1254-65. doi: $10.1111 /$ cas. 14339

51. Yu A, Wang Y, Bian Y, Chen L, Guo J, Shen W, et al. Il-1 $1 \beta$ Promotes the Nuclear Translocaiton of S100A4 Protein in Gastric Cancer Cells MGC803 and the Cell's Stem-Like Properties Through PI3K Pathway. J Cell Biochem (2018) 119(10):8163-73. doi: 10.1002/jcb.26813

52. Ma J, Song X, Xu X, Mou Y. Cancer-Associated Fibroblasts Promote the Chemo-resistance in Gastric Cancer Through Secreting Il-11 Targeting Jak/ Stat3/Bcl2 Pathway. Cancer Res Treat (2019) 51(1):194-210. doi: 10.4143/ crt.2018.031

53. Zhai J, Shen J, Xie G, Wu J, He M, Gao L, et al. Cancer-Associated FibroblastsDerived IL-8 Mediates Resistance to Cisplatin in Human Gastric Cancer. Cancer Lett (2019) 454:37-43. doi: 10.1016/j.canlet.2019.04.002

54. Li J, Wang L, He F, Li B, Han R. Long Noncoding RNA LINC00629 Restrains the Progression of Gastric Cancer by Upregulating AQP4 Through Competitively Binding to Mir-196b-5p. J Cell Physiol (2020) 235(3):2973-85. doi: $10.1002 / j c p .29203$

55. Chen Z, Zhu S, Hong J, Soutto M, Peng D, Belkhiri A, et al. Gastric TumourDerived ANGPT2 Regulation by DARPP-32 Promotes Angiogenesis. Gut (2016) 65(6):925-34. doi: 10.1136/gutjnl-2014-308416

56. Chivu Economescu M, Necula LG, Dragu D, Badea L, Dima SO, Tudor S, et al. Identification of Potential Biomarkers for Early and Advanced Gastric Adenocarcinoma Detection. Hepatogastroenterology (2010) 57(104):1453-64.

57. Li W, Wong CC, Zhang X, Kang W, Nakatsu G, Zhao Q, et al. CAB39L Elicited an anti-Warburg Effect Via a LKB1-AMPK-PGC1 $\alpha$ Axis to Inhibit Gastric Tumorigenesis. Oncogene (2018) 37(50):6383-98. doi: 10.1038/ s41388-018-0402-1
58. Xu Z, Lv H, Wang Y, Hu C, Chen S, Du Y, et al. Hand2-As1 Inhibits Gastric Adenocarcinoma Cells Proliferation and Aerobic Glycolysis Via miRNAs Sponge. Cancer Manag Res (2020) 12:3053-68. doi: 10.2147/CMAR.S222878

59. Feng C, She J, Chen X, Zhang Q, Zhang X, Wang Y, et al. Exosomal miR-196a-1 Promotes Gastric Cancer Cell Invasion and Metastasis by Targeting SFRP1. Nanomed (Lond) (2019) 14(19):2579-93. doi: 10.2217/nnm-2019-0053

60. Cui HB, Ge HE, Wang YS, Bai XY. MiR-208a Enhances Cell Proliferation and Invasion of Gastric Cancer by Targeting SFRP1 and Negatively Regulating MEG3. Int J Biochem Cell Biol (2018) 102:31-9. doi: 10.1016/ j.biocel.2018.06.004

61. Lin R, Zhang H, Yuan Y, He Q, Zhou J, Li S, et al. Fatty Acid Oxidation Controls Cd8. Cancer Immunol Res (2020) 8(4):479-92. doi: 10.1158/23266066.CIR-19-0702

62. Shi JF, Xu SX, He P, Xi ZH. Expression of Carcinoembryonic AntigenRelated Cell Adhesion Molecule 1(CEACAM1) and its Correlation With Angiogenesis in Gastric Cancer. Pathol Res Pract (2014) 210(8):473-6. doi: 10.1016/j.prp.2014.03.014

63. Zhang Y, Zang M, Li J, Ji J, Zhang J, Liu X, et al. CEACAM6 Promotes Tumor Migration, Invasion, and Metastasis in Gastric Cancer. Acta Biochim Biophys Sin (Shanghai) (2014) 46(4):283-90. doi: 10.1093/abbs/gmu001

64. Xu T, Zhang R, Dong M, Zhang Z, Li H, Zhan C, et al. Osteoglycin (Ogn) Inhibits Cell Proliferation and Invasiveness in Breast Cancer Via PI3K/Akt/ mTOR Signaling Pathway. Onco Targets Ther (2019) 12:10639-50. doi: 10.2147/OTT.S222967

65. Xu C, Ooi WF, Qamra A, Tan J, Chua BY, Ho SWT, et al. Pathway Mapping Identifies Wild-Type. Gut (2020) 69(2):231-42. doi: 10.1136/gutjnl-2018-318025

66. Yi J, Ren L, Wu J, Li W, Zheng X, Du G, et al. Apolipoprotein C1 (APOC1) as a Novel Diagnostic and Prognostic Biomarker for Gastric Cancer. Ann Transl Med (2019) 7(16):380. doi: 10.21037/atm.2019.07.59

67. Shi X, Xu J, Wang J, Cui M, Gao Y, Niu H, et al. Expression Analysis of Apolipoprotein E and its Associated Genes in Gastric Cancer. Oncol Lett (2015) 10(3):1309-14. doi: 10.3892/ol.2015.3447

68. Sakashita K, Tanaka F, Zhang X, Mimori K, Kamohara Y, Inoue H, et al. Clinical Significance of ApoE Expression in Human Gastric Cancer. Oncol Rep (2008) 20(6):1313-9. doi: 10.3892/or_00000146

69. Ezzeddini R, Taghikhani M, Somi MH, Samadi N, Rasaee MJ. Clinical Importance of FASN in Relation to HIF- $1 \alpha$ and SREBP-1c in Gastric Adenocarcinoma. Life Sci (2019) 224:169-76. doi: 10.1016/j.lfs.2019.03.056

70. Takada H, Imoto I, Tsuda H, Nakanishi Y, Sakakura C, Mitsufuji S, et al. Genomic Loss and Epigenetic Silencing of Very-Low-Density Lipoprotein Receptor Involved in Gastric Carcinogenesis. Oncogene (2006) 25(49):655462. doi: 10.1038/sj.onc. 1209657

71. Ma L, Wang L, Nelson AT, Han C, He S, Henn MA, et al. 27Hydroxycholesterol Acts on Myeloid Immune Cells to Induce T Cell Dysfunction, Promoting Breast Cancer Progression. Cancer Lett (2020) 493:266-83. doi: $10.1016 /$ j.canlet.2020.08.020

72. Sánchez-Zauco N, Torres J, Gómez A, Camorlinga-Ponce M, Muñoz-Pérez L, Herrera-Goepfert R, et al. Correction to: Circulating Blood Levels of IL-6, Ifn- $\gamma$, and IL-10 as Potential Diagnostic Biomarkers in Gastric Cancer: A Controlled Study. BMC Cancer (2017) 17(1):669. doi: 10.1186/s12885-017$3657-y$

73. Shen Z, Seppänen H, Vainionpää S, Ye Y, Wang S, Mustonen H, et al. Il10, IL11, IL18 are Differently Expressed in CD14+ Tams and Play Different Role in Regulating the Invasion of Gastric Cancer Cells Under Hypoxia. Cytokine (2012) 59(2):352-7. doi: 10.1016/j.cyto.2012.04.033

74. Zuo X, Deguchi Y, Xu W, Liu Y, Li HS, Wei D, et al. PPARD and Interferon Gamma Promote Transformation of Gastric Progenitor Cells and Tumorigenesis in Mice. Gastroenterology (2019) 157(1):163-78. doi: 10.1053/j.gastro.2019.03.018

75. Ayers M, Lunceford J, Nebozhyn M, Murphy E, Loboda A, Kaufman DR, et al. Ifn- $\gamma$-Related mRNA Profile Predicts Clinical Response to PD-1 Blockade. J Clin Invest (2017) 127(8):2930-40. doi: 10.1172/JCI91190

76. Wei Y, Wang T, Song H, Tian L, Lyu G, Zhao L, et al. C-C Motif Chemokine 22 Ligand (CCL22) Concentrations in Sera of Gastric Cancer Patients are Related to Peritoneal Metastasis and Predict Recurrence Within One Year After Radical Gastrectomy. J Surg Res (2017) 211:266-78. doi: 10.1016/j.jss.2016.11.067

77. Wei C, Yang C, Wang S, Shi D, Zhang C, Lin X, et al. M2 Macrophages Confer Resistance to 5-Fluorouracil in Colorectal Cancer Through the 
Activation of CCL22/PI3K/AKT Signaling. Onco Targets Ther (2019) 12:3051-63. doi: 10.2147/OTT.S198126

78. Ji L, Qian W, Gui L, Ji Z, Yin P, Lin GN, et al. Blockade of $\beta$-CateninInduced CCL28 Suppresses Gastric Cancer Progression Via Inhibition of Treg Cell Infiltration. Cancer Res (2020) 80(10):2004-16. doi: 10.1158/00085472.CAN-19-3074

79. Xu J, Yu Y, He X, Niu N, Li X, Zhang R, et al. Tumor-Associated Macrophages Induce Invasion and Poor Prognosis in Human Gastric Cancer in a cyclooxygenase-2/MMP9-dependent Manner. Am J Transl Res (2019) 11(9):6040-54

80. Jorge YC, Mataruco MM, Araújo LP, Rossi AF, de Oliveira JG, Valsechi MC, et al. Expression of annexin-A1 and Galectin-1 Anti-Inflammatory Proteins and mRNA in Chronic Gastritis and Gastric Cancer. Mediators Inflammation (2013) 2013:152860. doi: 10.1155/2013/152860

81. Lin LL, Huang HC, Juan HF. Revealing the Molecular Mechanism of Gastric Cancer Marker Annexin A4 in Cancer Cell Proliferation Using Exon Arrays. PloS One (2012) 7(9):e44615. doi: 10.1371/journal.pone.0044615

82. Jiang J, Zhao W, Tang Q, Wang B, Li X, Feng Z. Over Expression of Amphiregulin Promoted Malignant Progression in Gastric Cancer. Pathol Res Pract (2019) 215(10):152576. doi: 10.1016/j.prp.2019.152576

83. Wang H, Hu L, Zang M, Zhang B, Duan Y, Fan Z, et al. REG4 Promotes Peritoneal Metastasis of Gastric Cancer Through GPR37. Oncotarget (2016) 7(19):27874-88. doi: 10.18632/oncotarget.8442

84. Alpízar-Alpízar W, Laerum OD, Illemann M, Ramírez JA, Arias A, MalespínBendaña W, et al. Neutrophil Gelatinase-Associated Lipocalin (NGAL/Lcn2) is Upregulated in Gastric Mucosa Infected With Helicobacter Pylori. Virchows Arch (2009) 455(3):225-33. doi: 10.1007/s00428-009-0825-8

85. Wang HJ, He XJ, Ma YY, Jiang XT, Xia YJ, Ye ZY, et al. Expressions of Neutrophil Gelatinase-Associated Lipocalin in Gastric Cancer: A Potential Biomarker for Prognosis and an Ancillary Diagnostic Test. Anat Rec (Hoboken) (2010) 293(11):1855-63. doi: 10.1002/ar.21230

86. Liu JN, Wang HB, Zhou CC, Hu SY. CEACAM5 has Different Expression Patterns in Gastric non-Neoplastic and Neoplastic Lesions and Cytoplasmic Staining is a Marker for Evaluation of Tumor Progression in Gastric Adenocarcinoma. Pathol Res Pract (2014) 210(10):686-93. doi: 10.1016/ j.prp.2014.06.024

87. Zhou J, Fan X, Chen N, Zhou F, Dong J, Nie Y, et al. Identification of CEACAM5 as a Biomarker for Prewarning and Prognosis in Gastric Cancer. J Histochem Cytochem (2015) 63(12):922-30. doi: 10.1369/ 0022155415609098

88. Qiu YS, Liao GJ, Jiang NN. REG3A Overexpression Suppresses Gastric Cancer Cell Invasion, Proliferation and Promotes Apoptosis Through PI3K/ Akt Signaling Pathway. Int J Mol Med (2018) 41(6):3167-74. doi: 10.3892/ ijmm. 2018.3520

89. Choi B, Suh Y, Kim WH, Christa L, Park J, Bae CD. Downregulation of Regenerating Islet-Derived 3 Alpha (REG3A) in Primary Human Gastric Adenocarcinomas. Exp Mol Med (2007) 39(6):796-804. doi: 10.1038/ emm. 2007.86

90. Li L, Zhu Z, Zhao Y, Zhang Q, Wu X, Miao B, et al. Fn1, SPARC, and SERPINE1 are Highly Expressed and Significantly Related to a Poor Prognosis of Gastric Adenocarcinoma Revealed by Microarray and Bioinformatics. Sci Rep (2019) 9(1):7827. doi: 10.1038/s41598-019-43924-x

91. Thiel A, Mrena J, Ristimäki A. Cyclooxygenase-2 and Gastric Cancer. Cancer Metastasis Rev (2011) 30(3-4):387-95. doi: 10.1007/s10555-011-9312-1

92. Zhou R, Sun J, He C, Huang C, Yu H. CCL19 Suppresses Gastric Cancer Cell Proliferation, Migration, and Invasion Through the CCL19/CCR7/AIM2 Pathway. Hum Cell (2020) 33(4):1120-32. doi: 10.1007/s13577-020-00375-1

93. Prestin K, Olbert M, Hussner J, Isenegger TL, Gliesche DG, Böttcher K, et al. Modulation of Expression of the Nuclear Receptor NR0B2 (Small Heterodimer Partner 1) and its Impact on Proliferation of Renal Carcinoma Cells. Onco Targets Ther (2016) 9:4867-78. doi: 10.2147/OTT.S106926

94. Xiang Z, Zhou ZJ, Xia GK, Zhang XH, Wei ZW, Zhu JT, et al. A Positive Crosstalk Between CXCR4 and CXCR2 Promotes Gastric Cancer Metastasis. Oncogene (2017) 36(36):5122-33. doi: 10.1038/onc.2017.108

95. Hu C, Lin F, Zhu G, Xue X, Ding Y, Zhao Z, et al. Abnormal Hypermethylation of Promoter Region Downregulates Chemokine CXC Ligand 14 Expression in Gastric Cancer. Int J Oncol (2013) 43(5):1487-94. doi: $10.3892 /$ ijo.2013.2078
96. Niu W, Guo LY, Zhang JY, Ji T, Mao D, Li XF, et al. E2F1-Induced Upregulation of Lncrna HCG18 Stimulates Proliferation and Migration in Gastric Cancer by Binding to Mir-197-3p. Eur Rev Med Pharmacol Sci (2020) 24(19):9949-56. doi: 10.26355/eurrev_202010_23207

97. Chong X, Peng R, Sun Y, Zhang L, Zhang Z. Identification of Key Genes in Gastric Cancer by Bioinformatics Analysis. BioMed Res Int (2020) 2020:7658230. doi: 10.1155/2020/7658230

98. Zhang Y, Qin L, Ma X, Wang Y, Wu Y, Jiang J. Coexpression of Matrix Metalloproteinase-7 and Tissue Inhibitor of Metalloproteinase-1 as a Prognostic Biomarker in Gastric Cancer. Dis Markers (2020) 2020:8831466. doi: 10.1155/2020/8831466

99. Zhao Z, Zhang C, Zhao Q. S100A9 as a Novel Diagnostic and Prognostic Biomarker in Human Gastric Cancer. Scand J Gastroenterol (2020) 55 (3):338-46. doi: 10.1080/00365521.2020.1737883

100. Wu W, Juan WC, Liang CR, Yeoh KG, So J, Chung MC. S100a9, GIF and AAT as Potential Combinatorial Biomarkers in Gastric Cancer Diagnosis and Prognosis. Proteomics Clin Appl (2012) 6(3-4):152-62. doi: 10.1002/ prca.201100050

101. Gordon-Weeks A, Lim SY, Yuzhalin A, Lucotti S, Vermeer JAF, Jones K, et al. Tumour-Derived Laminin $\alpha 5$ (Lama5) Promotes Colorectal Liver Metastasis Growth, Branching Angiogenesis and Notch Pathway Inhibition. Cancers (Basel) (2019) 11(5):630. doi: 10.3390/cancers11050630

102. Yu Z, Li Z, Wang C, Pan T, Chang X, Wang X, et al. Oncostatin M Receptor, Positively Regulated by SP1, Promotes Gastric Cancer Growth and Metastasis Upon Treatment With Oncostatin M. Gastric Cancer (2019) 22 (5):955-66. doi: 10.1007/s10120-019-00934-y

103. Mukai S, Oue $\mathrm{N}$, Oshima $\mathrm{T}$, Imai $\mathrm{T}$, Sekino $\mathrm{Y}$, Honma $\mathrm{R}$, et al. Overexpression of PCDHB9 Promotes Peritoneal Metastasis and Correlates With Poor Prognosis in Patients With Gastric Cancer. J Pathol (2017) 243(1):100-10. doi: 10.1002/path.4931

104. Katoh Y, Katoh M. Comparative Integromics on Ephrin Family. Oncol Rep (2006) 15(5):1391-5. doi: 10.3892/or.15.5.1391

105. Guo Y, Yin J, Wang Z, Zha L. Overexpression of Platelet-Derived Growth Factor-B Increases the Growth, Invasion, and Angiogenesis of Gastric Carcinoma Cells Through Protein Kinase B. Neoplasma (2013) 60(6):60512. doi: 10.4149/neo_2013_078

106. Ye YW, Zhou Y, Yuan L, Wang CM, Du CY, Zhou XY, et al. Fibroblast Growth Factor Receptor 4 Regulates Proliferation and Antiapoptosis During Gastric Cancer Progression. Cancer (2011) 117(23):5304-13. doi: 10.1002/cncr.26207

107. Yan S, Wang Y, Chen M, Li G, Fan J. Deregulated SLC2A1 Promotes Tumor Cell Proliferation and Metastasis in Gastric Cancer. Int J Mol Sci (2015) 16 (7):16144-57. doi: 10.3390/ijms160716144

108. Li C, Zhang J, Wu H, Li L, Yang C, Song S, et al. Lectin-Like Oxidized LowDensity Lipoprotein Receptor-1 Facilitates Metastasis of Gastric Cancer Through Driving Epithelial-Mesenchymal Transition and PI3K/Akt/ GSK3ß Activation. Sci Rep (2017) 7:45275. doi: 10.1038/srep45275

109. Wan S, Xi M, Zhao HB, Hua W, Liu YL, Zhou YL, et al. HMGCS2 Functions as a Tumor Suppressor and has a Prognostic Impact in Prostate Cancer. Pathol Res Pract (2019) 215(8):152464. doi: 10.1016/j.prp.2019.152464

110. Li Z, Wang Y, Dong S, Ge C, Xiao Y, Li R, et al. Association of CXCR1 and 2 Expressions With Gastric Cancer Metastasis in Ex Vivo and Tumor Cell Invasion In Vitro. Cytokine (2014) 69(1):6-13. doi: 10.1016/j.cyto.2014.05.004

111. Wang J, Hu W, Wu X, Wang K, Yu J, Luo B, et al. CXCR1 Promotes Malignant Behavior of Gastric Cancer Cells In Vitro and In Vivo in AKT and ERK1/2 Phosphorylation. Int J Oncol (2016) 48(5):2184-96. doi: 10.3892/ ijo.2016.3428

112. Hou XL, Ji CD, Tang J, Wang YX, Xiang DF, Li HQ, et al. FPR2 Promotes Invasion and Metastasis of Gastric Cancer Cells and Predicts the Prognosis of Patients. Sci Rep (2017) 7(1):3153. doi: 10.1038/s41598-017-03368-7

113. Li ML, Zhang JC, Li SG, Wu WG, Rao LH, Dong P, et al. Characteristic Gene Expression Profiles in the Progression From Normal Gastric Epithelial Cells to Moderate Gastric Epithelial Dysplasia and to Gastric Cancer. Chin Med J (Engl) (2012) 125(10):1777-83

114. Agarwal R, Mori Y, Cheng Y, Jin Z, Olaru AV, Hamilton JP, et al. Silencing of claudin-11 is Associated With Increased Invasiveness of Gastric Cancer Cells. PloS One (2009) 4(11):e8002. doi: 10.1371/journal.pone.0008002

115. Jang BG, Lee BL, Kim WH. Olfactomedin-Related Proteins 4 (OLFM4) Expression is Involved in Early Gastric Carcinogenesis and of Prognostic 
Significance in Advanced Gastric Cancer. Virchows Arch (2015) 467(3):28594. doi: 10.1007/s00428-015-1793-9

116. Choi B, Lee HJ, Min J, Choe HN, Choi YS, Son YG, et al. Plasma Expression of the Intestinal Metaplasia Markers CDH17 and TFF3 in Patients With Gastric Cancer. Cancer Biomark (2017) 19(3):231-9. doi: 10.3233/CBM-160147

117. Qiu F, Xiong JP, Deng J, Xiang XJ. TRIM29 Functions as an Oncogene in Gastric Cancer and is Regulated by Mir-185. Int J Clin Exp Pathol (2015) 8(5):5053-61.

118. Kosaka Y, Inoue H, Ohmachi T, Yokoe T, Matsumoto T, Mimori K, et al. Tripartite Motif-Containing 29 (TRIM29) is a Novel Marker for Lymph Node Metastasis in Gastric Cancer. Ann Surg Oncol (2007) 14(9):2543-9. doi: 10.1245/s10434-007-9461-1

119. Kanda M, Shimizu D, Tanaka H, Tanaka C, Kobayashi D, Hayashi M, et al. Significance of SYT8 for the Detection, Prediction, and Treatment of Peritoneal Metastasis From Gastric Cancer. Ann Surg (2018) 267(3):495503. doi: $10.1097 /$ SLA.0000000000002096

120. Xu LP, Qiu HB, Yuan SQ, Chen YM, Zhou ZW, Chen YB. Downregulation of PSCA Promotes Gastric Cancer Proliferation and is Related to Poor Prognosis. J Cancer (2020) 11(9):2708-15. doi: 10.7150/jca.33575

121. Dai J, Zhang N, Wang J, Chen M, Chen J. Gastrokine-2 is Downregulated in Gastric Cancer and its Restoration Suppresses Gastric Tumorigenesis and Cancer Metastasis. Tumour Biol (2014) 35(5):4199-207. doi: 10.1007/s13277-013-1550-0

122. Yamashita S, Tsujino Y, Moriguchi K, Tatematsu M, Ushijima T. Chemical Genomic Screening for Methylation-Silenced Genes in Gastric Cancer Cell Lines Using 5-Aza-2'-Deoxycytidine Treatment and Oligonucleotide Microarray. Cancer Sci (2006) 97(1):64-71. doi: 10.1111/j.1349-7006.2006.00136.x

123. Siegel RL, Miller KD, Jemal A. Cancer Statistics, 2017. CA Cancer J Clin (2017) 67(1):7-30. doi: 10.3322/caac.21387

124. Correa P, Houghton J. Carcinogenesis of Helicobacter Pylori. Gastroenterology (2007) 133(2):659-72. doi: 10.1053/j.gastro.2007.06.026

125. Yu Y. Evaluation of Traditional Pathological Classification At Molecular Classification Era for Gastric Cancer. Zhonghua Wei Chang Wai Ke Za Zhi (2014) 17(1):18-20.

126. Sarriugarte Lasarte A, Garcĺa Alberdi E, Martinez Indart L, Gutierrez Grijalba O, Albarez Abad I, Guerra Lerma M, et al. "From Lauren's Diffuse Gastric Cancer to WHO's Poorly Cohesive Carcinoma." Clinicopathological and Prognostic Characteristics. Rev Esp Enferm Dig (2020). doi: 10.17235/reed.2020.7184/2020

127. Ge S, Xia X, Ding C, Zhen B, Zhou Q, Feng J, et al. A Proteomic Landscape of Diffuse-Type Gastric Cancer. Nat Commun (2018) 9(1):1012. doi: 10.1038/ s41467-018-03121-2

128. Verkman AS, Hara-Chikuma M, Papadopoulos MC. Aquaporins-New Players in Cancer Biology. J Mol Med (Berl) (2008) 86(5):523-9. doi: 10.1007/s00109-008-0303-9

129. Chen Q, Zhu L, Zheng B, Wang J, Song X, Zheng W, et al. Effect of AQP9 Expression in Androgen-Independent Prostate Cancer Cell Pc3. Int J Mol Sci (2016) 17(5):738. doi: 10.3390/ijms17050738

130. Warth A, Mittelbronn M, Hülper P, Erdlenbruch B, Wolburg H. Expression of the Water Channel Protein Aquaporin-9 in Malignant Brain Tumors. Appl Immunohistochem Mol Morphol (2007) 15(2):193-8. doi: 10.1097/ 01.pai.0000213110.05108.e9

131. Zhang WG, Li CF, Liu M, Chen XF, Shuai K, Kong X, et al. Aquaporin 9 is DownRegulated in Hepatocellular Carcinoma and its Over-Expression Suppresses Hepatoma Cell Invasion Through Inhibiting Epithelial-to-Mesenchymal Transition. Cancer Lett (2016) 378(2):111-9. doi: 10.1016/j.canlet.2016.05.021

132. Huang D, Feng X, Liu Y, Deng Y, Chen H, Chen D, et al. AQP9-Induced Cell Cycle Arrest is Associated With RAS Activation and Improves Chemotherapy Treatment Efficacy in Colorectal Cancer. Cell Death Dis (2017) 8(6):e2894. doi: 10.1038/cddis.2017.282

133. De Santis S, Serino G, Fiorentino MR, Galleggiante V, Gena P, Verna G, et al. Corrigendum: Aquaporin-9 Contributes to the Maturation Process and Inflammatory Cytokine Secretion of Murine Dendritic Cells. Front Immunol (2019) 10:216. doi: 10.3389/fimmu.2019.00216

134. Moniaga CS, Watanabe S, Honda T, Nielsen S, Hara-Chikuma M. Aquaporin-9-expressing Neutrophils are Required for the Establishment of Contact Hypersensitivity. Sci Rep (2015) 5:15319. doi: 10.1038/srep15319

135. Zhu L, Ma N, Wang B, Wang L, Zhou C, Yan Y, et al. Significant Prognostic Values of Aquaporin mRNA Expression in Breast Cancer. Cancer Manag Res (2019) 11:1503-15. doi: 10.2147/CMAR.S193396
136. Liu X, Xu Q, Li Z, Xiong B. Integrated Analysis Identifies AQP9 Correlates With Immune Infiltration and Acts as a Prognosticator in Multiple Cancers. Sci Rep (2020) 10(1):20795. doi: 10.1038/s41598-020-77657-z

137. Thapa S, Chetry M, Huang K, Peng Y, Wang J, Wang J, et al. Significance of Aquaporins' Expression in the Prognosis of Gastric Cancer. Biosci Rep (2018) 38(3):BSR20171687. doi: 10.1042/BSR20171687

138. Komohara Y, Fujiwara Y, Ohnishi K, Shiraishi D, Takeya M. Contribution of Macrophage Polarization to Metabolic Diseases. J Atheroscler Thromb (2016) 23(1):10-7. doi: 10.5551/jat.32359

139. Zotti T, Polvere I, Voccola S, Vito P, Stilo R. Card14/Carma2 Signaling and its Role in Inflammatory Skin Disorders. Front Immunol (2018) 9:2167. doi: 10.3389/fimmu.2018.02167

140. Harden JL, Lewis SM, Pierson KC, Suárez-Fariñas M, Lentini T, Ortenzio FS, et al. CARD14 Expression in Dermal Endothelial Cells in Psoriasis. PloS One (2014) 9(11):e111255. doi: 10.1371/journal.pone.0111255

141. Jordan CT, Cao L, Roberson ED, Pierson KC, Yang CF, Joyce CE, et al. PSORS2 is Due to Mutations in CARD14. Am J Hum Genet (2012) 90 (5):784-95. doi: 10.1016/j.ajhg.2012.03.012

142. Scudiero I, Zotti T, Ferravante A, Vessichelli M, Vito P, Stilo R. Alternative Splicing of CARMA2/CARD14 Transcripts Generates Protein Variants With Differential Effect on NF- $\kappa b$ Activation and Endoplasmic Reticulum StressInduced Cell Death. J Cell Physiol (2011) 226(12):3121-31. doi: 10.1002/ jcp. 22667

143. Lim JY, Kim SW, Kim B, Park SJ. Knockdown of CARD14 Inhibits Cell Proliferation and Migration in Breast Cancer Cells. Anticancer Res (2020) 40 (4):1953-62. doi: 10.21873/anticanres.14150

144. Kasashima H, Yashiro M, Nakamae H, Kitayama K, Masuda G, Kinoshita H, et al. Cxcl1-Chemokine (C-X-C Motif) Receptor 2 Signaling Stimulates the Recruitment of Bone Marrow-Derived Mesenchymal Cells Into Diffuse-Type Gastric Cancer Stroma. Am J Pathol (2016) 186(11):3028-39. doi: 10.1016/ j.ajpath.2016.07.024

145. Acharyya S, Oskarsson T, Vanharanta S, Malladi S, Kim J, Morris PG, et al. A CXCL1 Paracrine Network Links Cancer Chemoresistance and Metastasis. Cell (2012) 150(1):165-78. doi: 10.1016/j.cell.2012.04.042

146. Steele CW, Karim SA, Leach JDG, Bailey P, Upstill-Goddard R, Rishi L, et al. Cxcr2 Inhibition Profoundly Suppresses Metastases and Augments Immunotherapy in Pancreatic Ductal Adenocarcinoma. Cancer Cell (2016) 29(6):832-45. doi: 10.1016/j.ccell.2016.04.014

147. Highfill SL, Cui Y, Giles AJ, Smith JP, Zhang H, Morse E, et al. Disruption of CXCR2-mediated MDSC Tumor Trafficking Enhances anti-PD1 Efficacy. Sci Transl Med (2014) 6(237):237ra67. doi: 10.1126/scitranslmed. 3007974

148. Izumi K, Fang LY, Mizokami A, Namiki M, Li L, Lin WJ, et al. Targeting the Androgen Receptor With siRNA Promotes Prostate Cancer Metastasis Through Enhanced Macrophage Recruitment Via CCL2/CCR2-induced STAT3 Activation. EMBO Mol Med (2013) 5(9):1383-401. doi: 10.1002/ emmm.201202367

149. Kasashima H, Yashiro M, Nakamae H, Masuda G, Kinoshita H, Morisaki T, et al. Clinicopathologic Significance of the CXCL1-CXCR2 Axis in the Tumor Microenvironment of Gastric Carcinoma. PloS One (2017) 12(6): e0178635. doi: 10.1371/journal.pone.0178635

150. Wang J, Hu W, Wang K, Yu J, Luo B, Luo G, et al. Repertaxin, an Inhibitor of the Chemokine Receptors CXCR1 and CXCR2, Inhibits Malignant Behavior of Human Gastric Cancer MKN45 Cells In Vitro and In Vivo and Enhances Efficacy of 5-Fluorouracil. Int J Oncol (2016) 48(4):1341-52. doi: 10.3892/ ijo.2016.3371

Conflict of Interest: The authors declare that the research was conducted in the absence of any commercial or financial relationships that could be construed as a potential conflict of interest.

Copyright (๑ 2021 Carino, Graziosi, Marchianò, Biagioli, Marino, Sepe, Zampella, Distrutti, Donini and Fiorucci. This is an open-access article distributed under the terms of the Creative Commons Attribution License (CC BY). The use, distribution or reproduction in other forums is permitted, provided the original author(s) and the copyright owner(s) are credited and that the original publication in this journal is cited, in accordance with accepted academic practice. No use, distribution or reproduction is permitted which does not comply with these terms. 